Article

\title{
The Higher Education Sustainability through Virtual Laboratories: The Spanish University as Case of Study
}

\author{
Esther Salmerón-Manzano ${ }^{1}$ and Francisco Manzano-Agugliaro ${ }^{2, *}$ (i) \\ 1 Faculty of Legal, Social and Human Sciences, Universidad Internacional de La Rioja (UNIR), Av. de la Paz, \\ 137, 26006 Logroño, Spain; esther.salmeron@unir.net \\ 2 Department of Engineering, ceiA3, University of Almeria, 04120 Almeria, Spain \\ * Correspondence: fmanzano@ual.es; Tel.: +34-950-015-693
}

Received: 30 September 2018; Accepted: 1 November 2018; Published: 4 November 2018

check for updates

\begin{abstract}
Education has been integrated into the globalization process supported by technological advances such as e-learning. The sustainability of the universities is one of the key points of the university survival, and they strongly depend on the number of students that can enroll in them. Thus, many of the educational institutions have had to develop their curricula based on the use new technologies. Without a doubt, virtual laboratories are the latest technology in this regard. The objective of this work is to determine which are the main institutions and research trends in relation to virtual laboratories. The methodology followed in this research was to perform a bibliometric analysis of the whole scientific production indexed in Scopus. The world's scientific production has been analysed in the following domains: first the trend over time, types of publications and countries, second the main subjects and keywords, third main institutions and their main topics, and fourth the main journals and proceedings that publish on this topic. After that, a case study was analysed in detailed as a representative country (Spain). The most productive institution in this field, Universidad de Educación a Distancia (UNED). If the ranking is established by average citations per published paper, the first three institutions are from the USA: Massachusetts Institute of Technology (MIT), University of Washington (Seattle), and Carnegie Mellon University. The scientific categories at world level and in the case of study are similar. First, there is the field of engineering followed by computer science and above all it highlights the wide spectrum of branches of knowledge in which this topic is published, which indicates the great acceptance of this teaching methodology in all fields of education. Finally, community detection has been applied to the case study and six clusters have been found: Virtual Reality, Users, E-learning, Programming, Automatic-robotics, Computer Simulation and Engineering Education. As a main conclusion, bibliographic analysis confirms that research in virtual laboratories is a very active field, where scientific productivity has exponentially increased over recent years in tandem with universities growth. Therefore, expectations are high in this field for the near future. The possibility of virtual laboratories opens up new perspectives for higher education sustainability, where the educational policies of countries could be reoriented.
\end{abstract}

Keywords: university; teaching innovation; virtual laboratories; learning; Spain; sustainability

\section{Introduction}

In the recent past, both scientific and technological advances were incipient, and education was developed in such a way that the individual could only be integrated into productive life within the schemes that governed its geographical environment. The source of knowledge was what was published in the books. Additionally, the communication with other individuals around the world was 
not easy. Thus, what happened at a certain time and place became a historical fact when it came to its knowledge. This made the world of education very local and limited for the future university graduate to become involved in the lifestyle of other countries. Therefore, an element that has marked the difference between the educational stages of the different periods is precisely the access, management and use of the information that students have been able to access.

Today, events happen so quickly that the human mind must be programmed to grasp everything that happens in the "here and now". The succession of occurrences with such speed that what astonishes us at one time, at another, is no longer topical, but gives way to others. This is the new dynamic that moves the world. The educational world in general is no exception; the development of technology has changed the concepts of distance, time and place, giving way to new practices and realities in every academic discipline and branch of knowledge [1]. This is illustrated by many examples in universities all over the world, Saudi Arabia [2], Spain [3], Portugal [4] or Korea [5].

Therefore, technological development (largely the Internet, remote communications and even social networks) is the step towards a universal phenomenon that has integrated and connected us in a shared virtual or physical reality [6]. This process is known as globalization.

Education has been integrated into the globalization process supported by technological advances such as electronic learning (e-learning), mobile learning (m-learning), game learning (g-learning) and ubiquitous learning (U-Learning), which have become an important support for current educational processes [7]. Thus, many of the educational institutions have had to develop their curricula based on the use of these new technologies, which becomes more sophisticated and, at the same time, more useful in the processes of teaching and learning.

The sustainability of universities is one of the milestones for their future development and depends to a large extent on the number of students who can enroll in them. The new graduates' requirements, especially in engineering and technology, require that they be able to perform and analyze experiments, implement experimental results, enhance processes, employ creativity, work as a team effectively and possess good communicational skills, as well as dominating the knowledge, techniques, skills and tools demanded by their disciplines [8]. Science and technology education are based on the students' experimentation in a laboratory, where theoretical models are confirmed, and the teaching is given a practical orientation [9]. There are two main types of laboratories: traditional or conventional laboratories (real laboratories), and non-traditional or simulation laboratories that include virtual laboratories. To this classification, one can add another, and that is whether these laboratories have local or remote access [10]. Figure 1 summarizes the four possible working environments for laboratories.

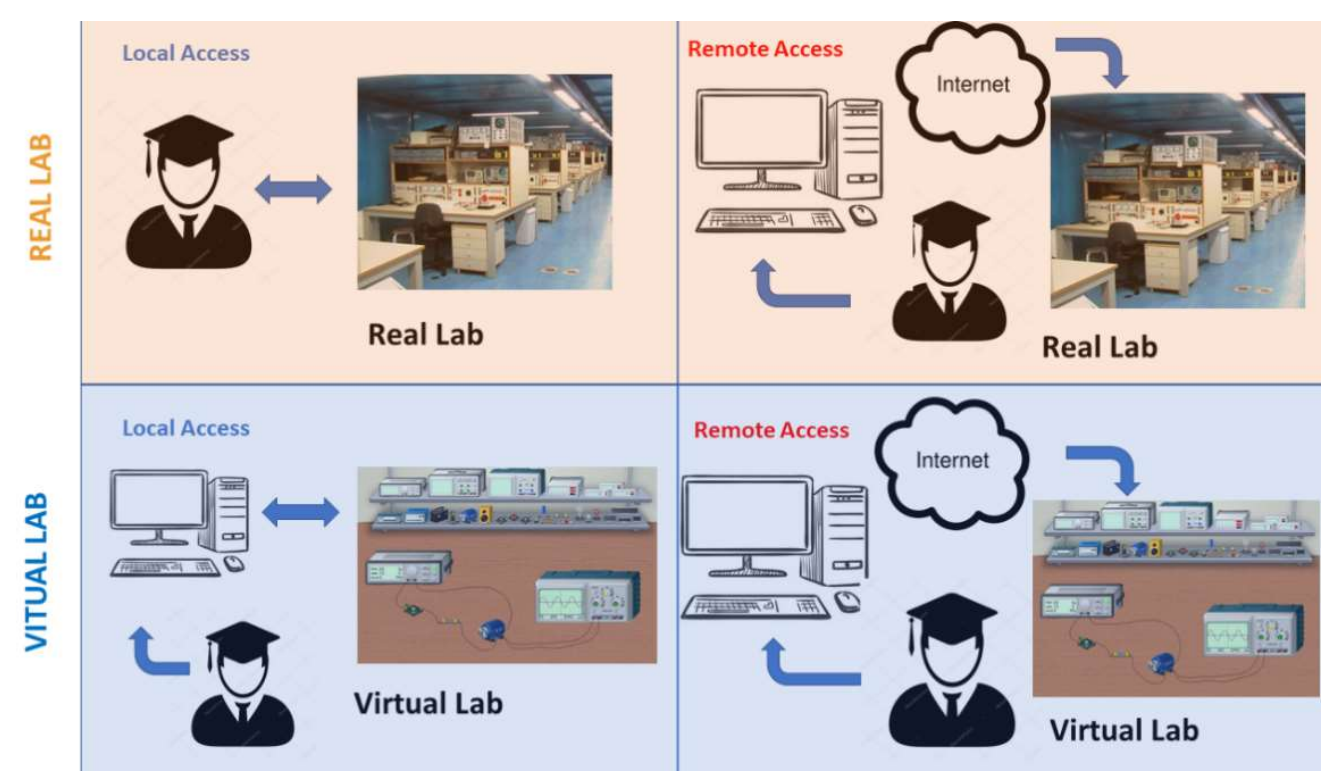

Figure 1. Types of working environments for laboratories. 
A virtual laboratory can be defined as an interactive environment for creating and conducting simulated experiments. Therefore, it consists of simulation programs, with objects that comprise data files, and tools that operate on these objects. Of course, not all laboratory practices can be computer simulated, nor can all the skills of a live job be acquired through virtual testing. However, virtual laboratories can be incorporated into tasks designed to make the most of the skills that need to be acquired, in which students can face situations that may not be feasible with the means at their disposal, and even improve the perception and interpretation of the different phenomena of reality. Virtual laboratories are born in response to this need [11], where ICT (Information and Communication Technology) opens a wide variety of new ways and methodologies to improve learning, as well as to expand educational opportunities for more students [12-14].

Among the main advantages of the virtual laboratories that make them more sustainable are [15]:

- Can be either local or remote access,

- The experiences are closer to a larger number of students,

- No limit to the number of opportunities,

- Experiencing without risk,

- No equipment can be damaged while learning how to use them,

- No laboratory equipment used,

- The place and time of the practices are made more flexible,

- A self-study mode can be considered where the input variables can be modified by the student,

And, among the main drawbacks, are the following [16]:

- They do not provide the same enriching experience as direct practice,

- The student may behave like a viewer,

- $\quad$ Laboratory reality can be distorted (if a proper simulation is not available), and

- Loss of teamwork skill due to excessive individualism on the part of the student.

It must be noted that the term virtual laboratory differs from the term virtual reality. This last term involves interactive digital environments as the illusion of being in a 3D space, ability to build and interact with the 3D objects, and often the digital representation themselves [17].

This paper aims to answer the following research question: what is the state of the art and what are the trends in virtual laboratory research? For this purpose, the following specific objectives have been set:

1. To systematically classify and quantify the published literature on virtual laboratories. Specifically, this analysis will focus on its trend over time, types of publications and countries that are involved in this research.

2. To highlight which are the main subjects' categories and keywords from the worldwide publications on this topic.

3. To highlight which are the most productive institutions (affiliations), which are their main topics, including their bibliometric indicators and their possible relationship in terms of available resources.

4. A representative country will be studied in depth as a case of study, to analyze how this scientific environment is among the universities, the main collaborators with these institutions, and the clusters associated with virtual laboratories publications and their main evolution over time.

\section{Methodology}

The presence of two huge scientific databases, Web of Science (WoS) and Scopus, poses the important question of the comparison and stability of statistics obtained from the different data sources [16]. Several studies have evaluated the overlap between both and conclude that they are comparable when the period from 1996 onwards is limited (Scopus coverage) [18,19]. In respect 
of journal coverage in the two large scientific databases such as Web of Science (WoS) and Scopus, a comparison analysis shows that the coverage of journals in $\operatorname{WoS}(13,605$ journals) is lower than that of Scopus (20,346 journals) [20], and the correlations between the results obtained with both databases for the number of articles and the number of citations received by the countries, as well as for their ranks, are extremely high $(\mathrm{R} 2 \approx 0.99)$ [21]. Therefore, only the Scopus data has been used. This methodology has been used successfully in different scientific fields [22-25].

Figure 2 shows a flowchart with the methodology used, where a main search in Scopus for work related to virtual laboratories is used. Once the main search information had been analyzed, a filter was applied according to the objective set, limiting it to the Spanish institutions, after which the results were exported to be analyzed with different programs.

The methodology included the following steps:

1. Global Data extraction. The main query has been made in the Scopus database: TITLE-ABS-KEY (virtual AND lab*). Each record contains the following subfields in CSV format (comma-separated values): Authors, Author Ids, Title, Year, Source title, Volume, Issue, Art. No., Page start, Page end, Page count, Cited by, DOI, Link, Document Type, Access Type, Source, EID.

2. Global Bibliometric data analysis. Thus, each subfield can be saved separately and analysed. For example, an analysis can be carried out to identify which are the main institutions or countries in this field.

3. Selection of a representative country as a case study. Among the countries that publish more than $1 \%$ of the world's scientific production on the topic of virtual laboratories, the one that is closest to the mean will be selected to be explored in detail. In this case, the search in the Scopus database will be TITLE-ABS-KEY (virtual AND lab*) AND (LIMIT-TO (AFFILCOUNTRY, "Selected country")).

4. Community detection. To see the research trends of the selected country, the community detection will be applied. This will allow us to group the scientific fields around which the scientific research is grouped in the selected country. The community detection of thematic clusters (community or cluster detection) was analyzed with VOSviewer (version, Manufacturer, City, US State abbrev. if applicable, Country) [26].

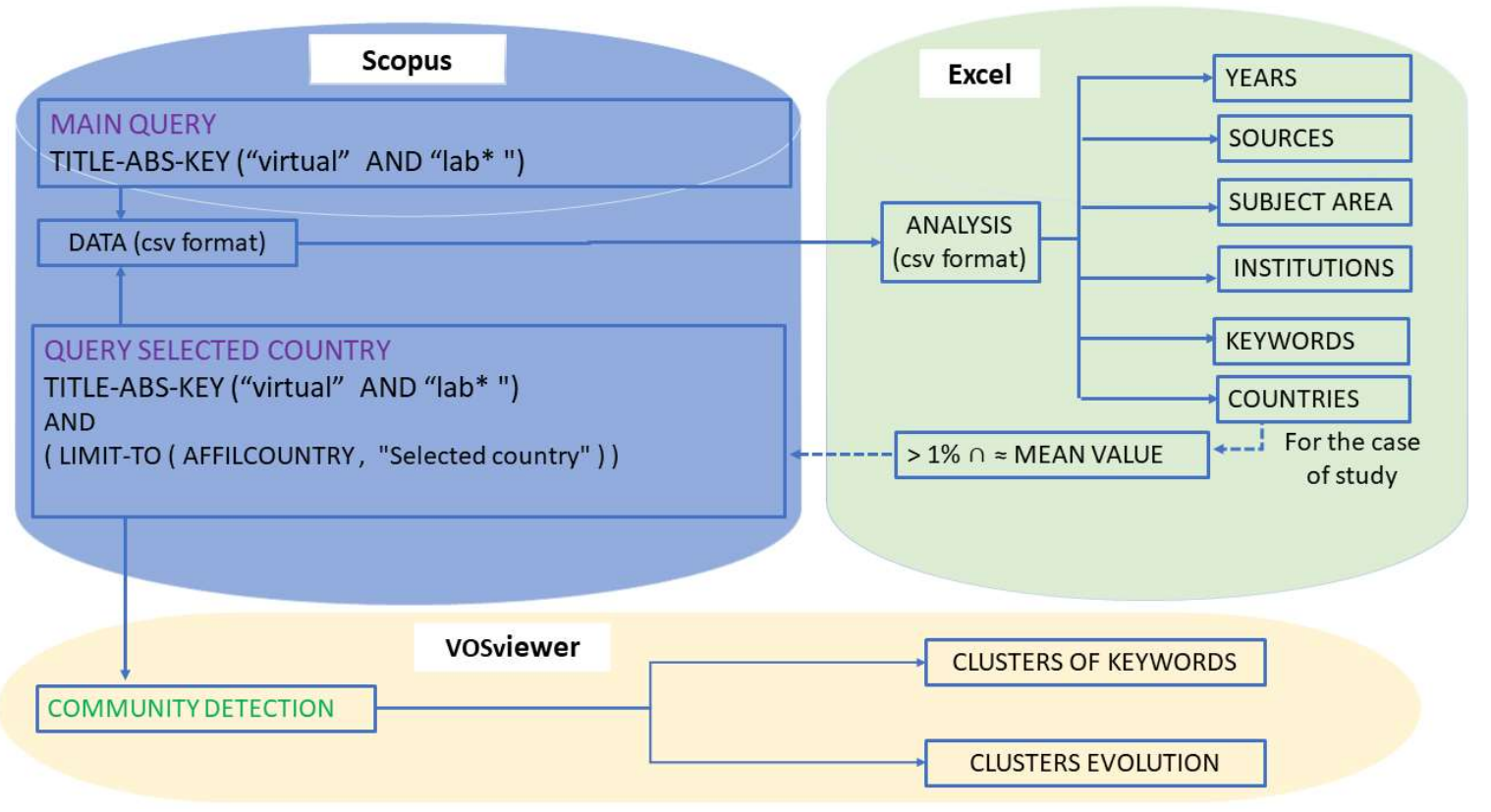

Figure 2. Flowchart of the methodology.

All publications that meet the query criteria have been included. There are no duplicate jobs, as each one has a unique DOI identifier (Digital Object Identifier); it is a unique alphanumeric string 
created to identify a piece of intellectual property in an online environment. The most popular use of the DOI system is the Crossref service, which enables a scientist to connect directly from a quotation reference to content cited on another publisher's platform [27]. During the data verification process, some inconsistencies have been detected, but it is a common problem to large databases due to the huge amount of information from a variety of sources they manage [28]. Specifically, from the results retrieved from Scopus, it is observed that the same keyword could be expressed as different forms; other times, the error is the origin affiliation, which can be expressed in different forms by researchers in their work. Therefore, it is necessary to apply refinement algorithms such as those included in the OpenRefine open-source tool [29], which applies several algorithms based on "Key Collision Methods" and "Nearest Neighbor Methods" to refine and integrate texts with words that express the same idea but have been written with some syntactic variations [30]. Finally, spreadsheets are used for grouping that refined information, so unique values are identified.

\section{Results and Discussion}

\subsection{Trend over Time, Types of Publications and Countries}

A total of 20,623 publication results related to virtual laboratories have been obtained in the Scopus database in the period 1984 to 2017, see Figure 3. If a trend line is represented, one can see that since 1990 it has been a linear upward trend, and since 2011 it has stabilized at around 1400 publications per year, showing great interest in this topic worldwide.

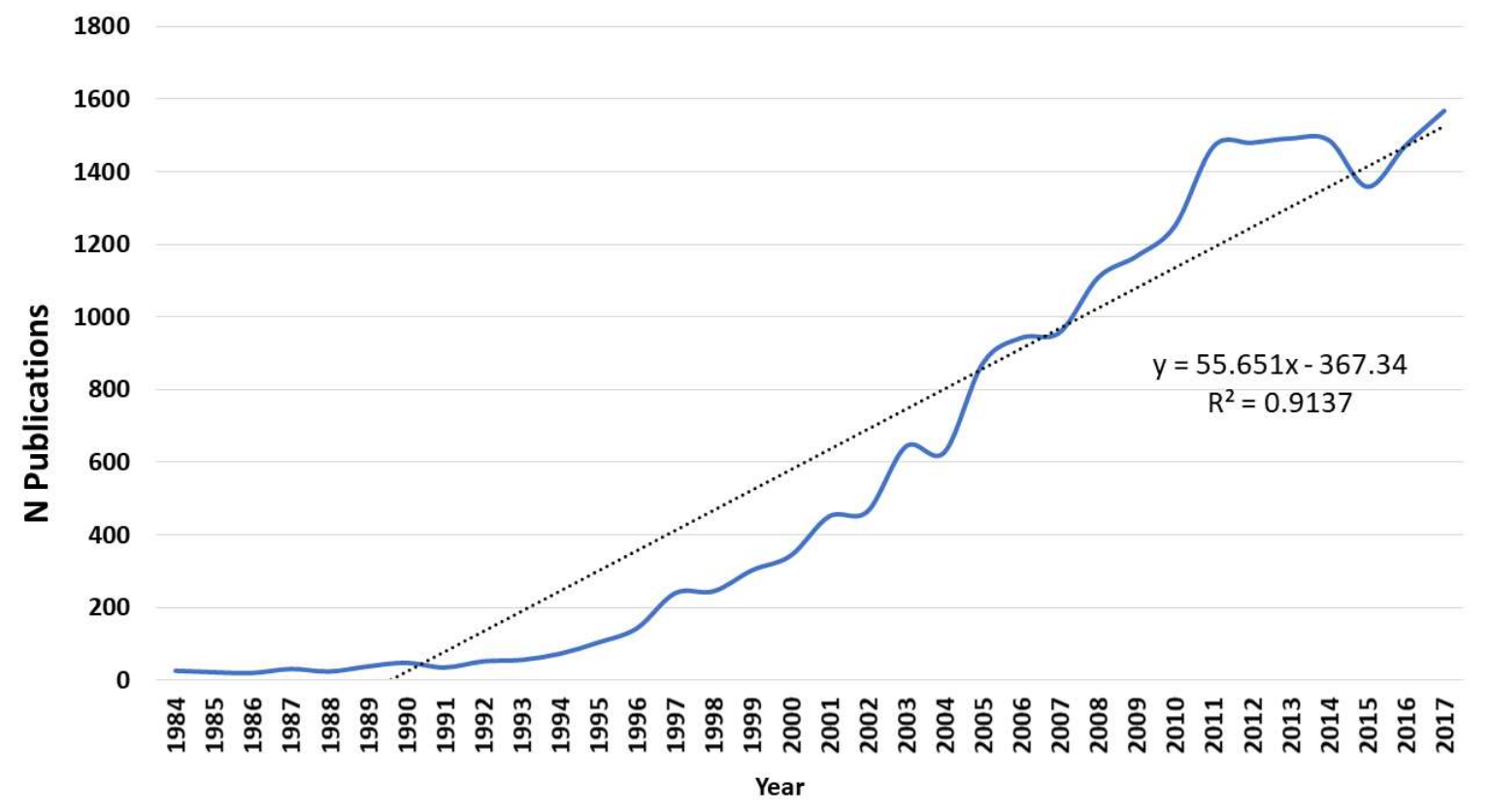

Figure 3. Time evolution of global publications in virtual laboratories.

Regarding the type of work published, the classification is determined directly by the Scopus database. It should be noted that an article is published in a journal and, on the other side, a conference paper or conference review is published in a congress or conference proceeding. It has been observed that $49 \%(10,061)$ are Conference Paper and, if we add the Conference Reviews $(471)$, which are $2 \%$, then most of the works are in Conference proceedings with $51 \%$ of the total. It should be noted that a Conference Review is a review published in a Conference Proceeding. Articles (8748) with $43 \%$ and Reviews (672) with 3\%, together account for $46 \%$, compared to Book Chapter and Book (458) with $2 \%$. When, as a percentage of publications in congress, it exceeds the number of journal articles [31,32], this indicates the novelty of the topic. On the other hand, when the themes are mature, the percentage of books is more significant than the percentage that has been observed. Regarding the top 10 countries, 
these are led by United States with 25\%, followed by China 13\%, Germany 5.6\%, United Kingdom 4.7\%, Spain 4.1\%, Italy 4\%, France 3.2\%, Canada 3\%, India 2.9\%, Japan 2.6\% and Australia 2.1\%. Figure 4 shows the wide geographical distribution of this issue throughout the world, except for some South American countries such as Paraguay and African countries.

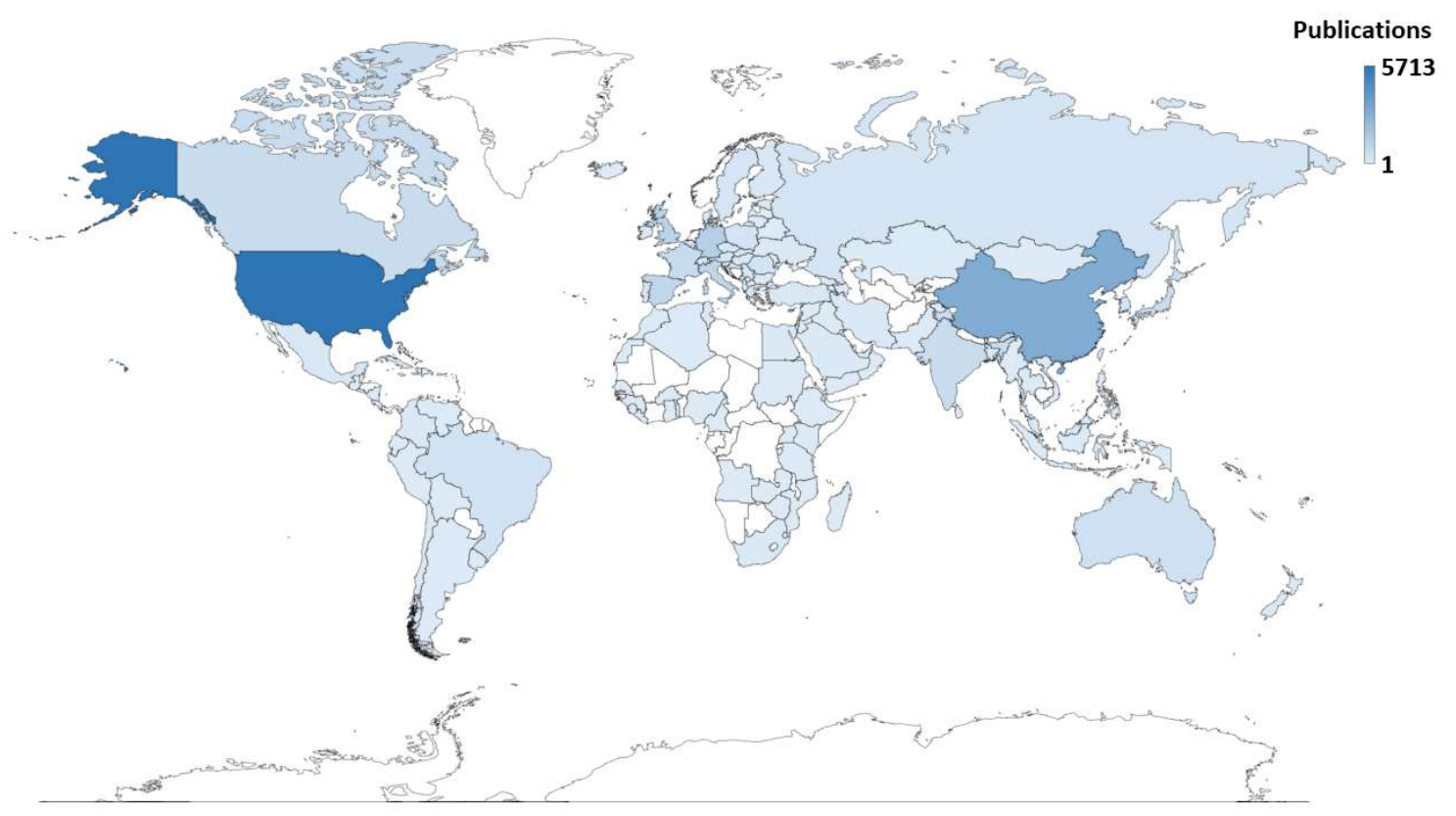

Figure 4. Worldwide geographical distribution in virtual laboratory publications.

\subsection{Subjects and Keywords from Worldwide Publications}

For the study of the topics, in the first instance, the classification that makes up the Scopus database, the subject category, will be considered. Figure 5 shows all the subject categories in which virtual laboratories appear. Two categories dominate this field, Engineering (26\%) and Computer Science $(22 \%)$, which together account for almost half of all publications. However, there are categories with a high percentage that a priori were not so expected: Social Sciences $8 \%$, Medicine $6 \%$, Mathematics 6\%, or Physics and Astronomy 6\%. In total, this theme appears in 27 categories, which makes us think of the great versatility of this type of work.

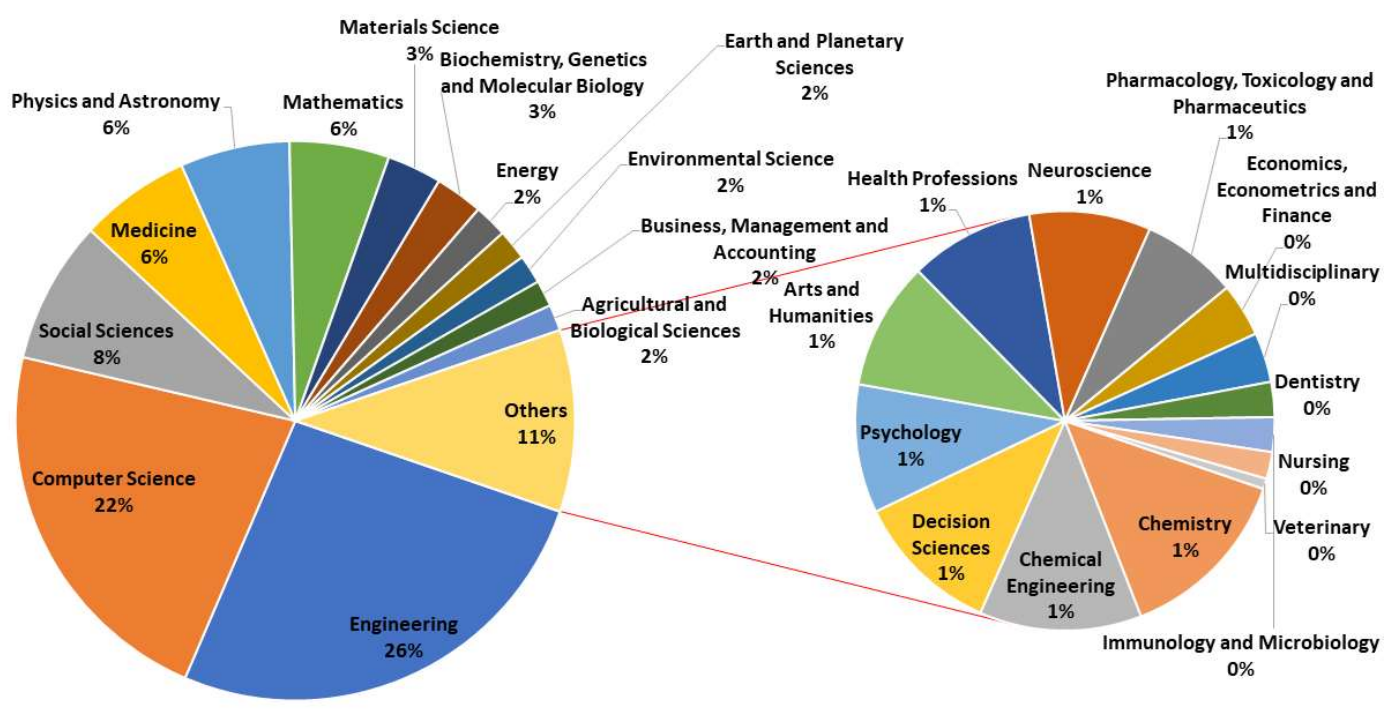

Figure 5. Subject category distribution in virtual laboratory publications. 
If a word cloud is made up with all keywords of publications related to virtual laboratories and considering their frequency in them, Figure 6 is obtained. It is observed that the dominant topic related to virtual laboratories is virtual reality. This term must be understood as an interactive computer-generated experience taking place within a simulated environment. Other terms as related to human factors, since Human and Humans appear in second and third place, which was expected because human interaction and its response is what is expected of them. Computer Simulation occupies an outstanding fourth place in importance, which is logical given that it is the tool that makes it possible and that, as we have seen in the subject categories, was had in $22 \%$ of the publications. The following keywords by importance were those related to teaching: Students, Education or Teaching-then, those related to instrumentation: Virtual Instrument or Virtual Laboratories. Engineering Education also plays an important role and is one of the main destinations for virtual laboratories, given the cost of teaching equipment. Finally, we will highlight the terms of E-learning and Distance Education that highlight the clear usefulness of virtual laboratories; however, as explained in the introduction, not all of them need to be with remote access and can be used in face-to-face laboratories.

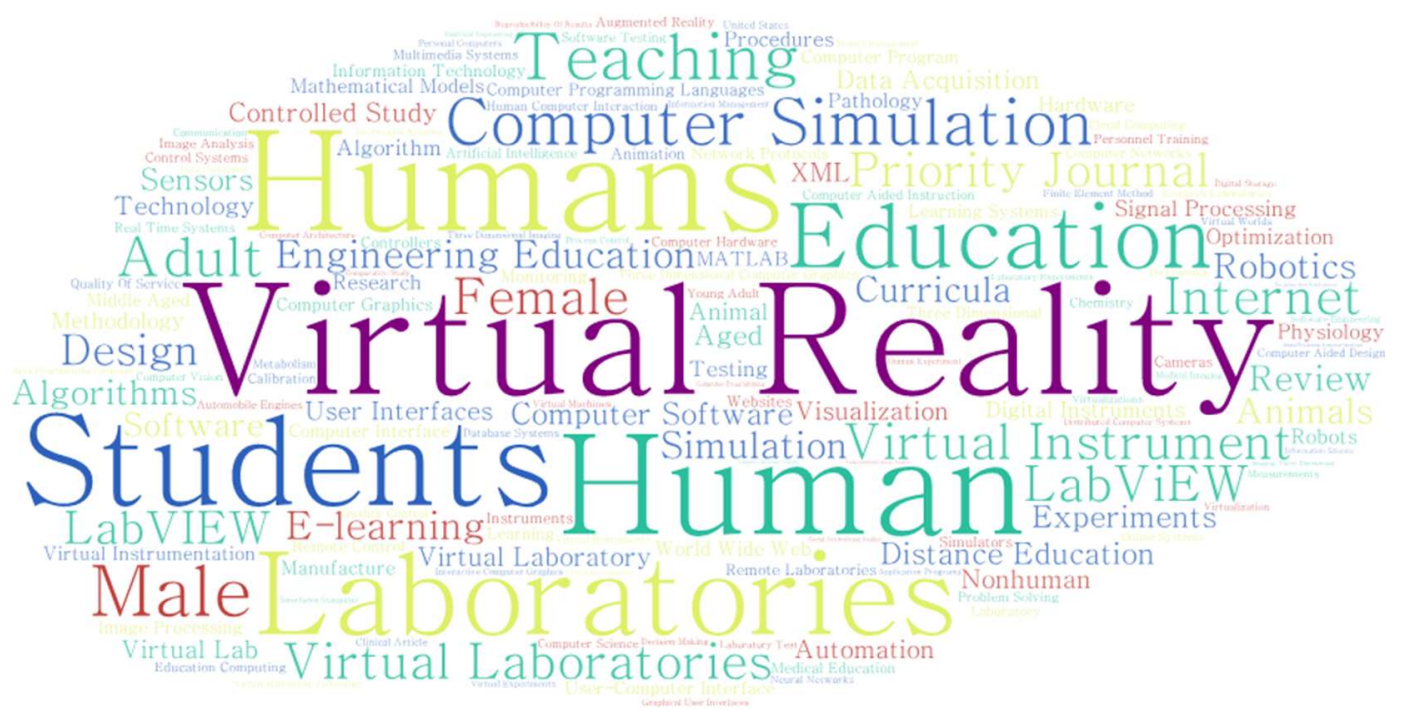

Figure 6. Cloud word with the keywords of virtual lab publications.

\subsection{Affiliations and Their Main Topics}

When the information regarding the affiliations needs to be analyzed, the data of the affiliations are downloaded for the search criteria, the virtual laboratories. The main affiliations that publish in this field are those shown in Figure 7, where those with more than 75 publications in this field have been reflected. Of these, the first is a Spanish institution and the one that appears in the 16th position. In this ranking based on the number of publications, there are six institutions from the USA and four from China.

If these institutions are given a simple bibliometric analysis, for example, the number of citations per document $(\mathrm{TC} / \mathrm{N})$, to see how much interest these works have aroused worldwide, see Table 1 . It is observed that this ranking change significantly in favour of the Massachusetts Institute of Technology (MIT) with more than 26 citations per document, then by the University of Washington (Seattle) with more than 24 citations per document. If one disregards those of the IEEE because it is not an academic institution, the Carnegie Mellon University is in third place with 23.7 citations per document. The three main institutions in this new ranking are from the USA.

If these institutions of Table 1 are analysed in terms of the resources available, the most important is the ratio of students per Academic Staff (Ns/As). It is observed that the most productive institution is the one with the highest ratio 19.5 (Ns/As), the Spanish Universidad Nacional de Educacion a Distancia, followed by University of Toronto with 18.7 and after University Politehnica of Bucharest 
with 18.2. On the other hand, those institutions dedicated mainly to the $\mathrm{PhD}$ are found with lower ratios, as it was expected, Chinese Academy of Sciences with 3.1, and Massachusetts Institute of Technology with 8.7 .

Table 1. Main institutions with research on virtual labs and their main bibliometric indicators.

\begin{tabular}{|c|c|c|c|c|c|c|c|c|}
\hline Institution & Country & Ns & Ns/As & $\mathbf{N}$ & TC & TC/N & $\mathbf{R}_{\mathbf{N}}$ & $\mathbf{R}_{\mathrm{TC} / \mathrm{N}}$ \\
\hline $\begin{array}{l}\text { Universidad Nacional de Educacion } \\
\text { a Distancia }\end{array}$ & Spain & 250,000 & 19.5 & 151 & 1124 & 7.44 & 1 & 12 \\
\hline Chinese Academy of Sciences & China & 45,000 & 3.1 & 143 & 895 & 6.26 & 2 & 13 \\
\hline Ministry of Education China & China & - & - & 132 & 521 & 3.95 & 3 & 15 \\
\hline $\begin{array}{l}\text { CNRS Centre National de la } \\
\text { Recherche Scientifique }\end{array}$ & France & - & - & 114 & 1685 & 14.78 & 4 & 9 \\
\hline Massachusetts Institute of Technology & USA & 11,177 & 8.7 & 111 & 2898 & 26.11 & 5 & 1 \\
\hline Tsinghua University & China & 36,912 & 11.9 & 101 & 1115 & 11.04 & 6 & 10 \\
\hline University of Michigan, Ann Arbor & USA & 44,718 & 6.7 & 93 & 1798 & 19.33 & 7 & 5 \\
\hline University Politehnica of Bucharest & Romania & 25,469 & 18.2 & 92 & 240 & 2.61 & 8 & 16 \\
\hline University of Washington, Seattle & USA & 44,945 & 11.4 & 92 & 2209 & 24.01 & 9 & 2 \\
\hline Purdue University & USA & 41.573 & 13.6 & 92 & 1653 & 17.97 & 10 & 6 \\
\hline University of Amsterdam & Netherland & 23,495 & 12.3 & 88 & 1403 & 15.94 & 11 & 7 \\
\hline Zhejiang University & China & 50,051 & 14.1 & 86 & 344 & 4.00 & 12 & 14 \\
\hline IEEE & USA & - & - & 83 & 1992 & 24.00 & 13 & 3 \\
\hline Carnegie Mellon University & USA & 12,676 & 13.5 & 78 & 1850 & 23.72 & 14 & 4 \\
\hline University of Toronto & Canada & 69,427 & 18.7 & 76 & 1190 & 15.66 & 15 & 8 \\
\hline
\end{tabular}

Ns: Number of students; As: Academic Staff; N: Number of publications; TC: Total Citations; TC/N: Citations per Document; $\mathrm{R}_{\mathrm{N}}$ : Rank by number of publications; $\mathrm{R}_{\mathrm{TC} / \mathrm{N}}$ : Rank by Total Citations per publication.

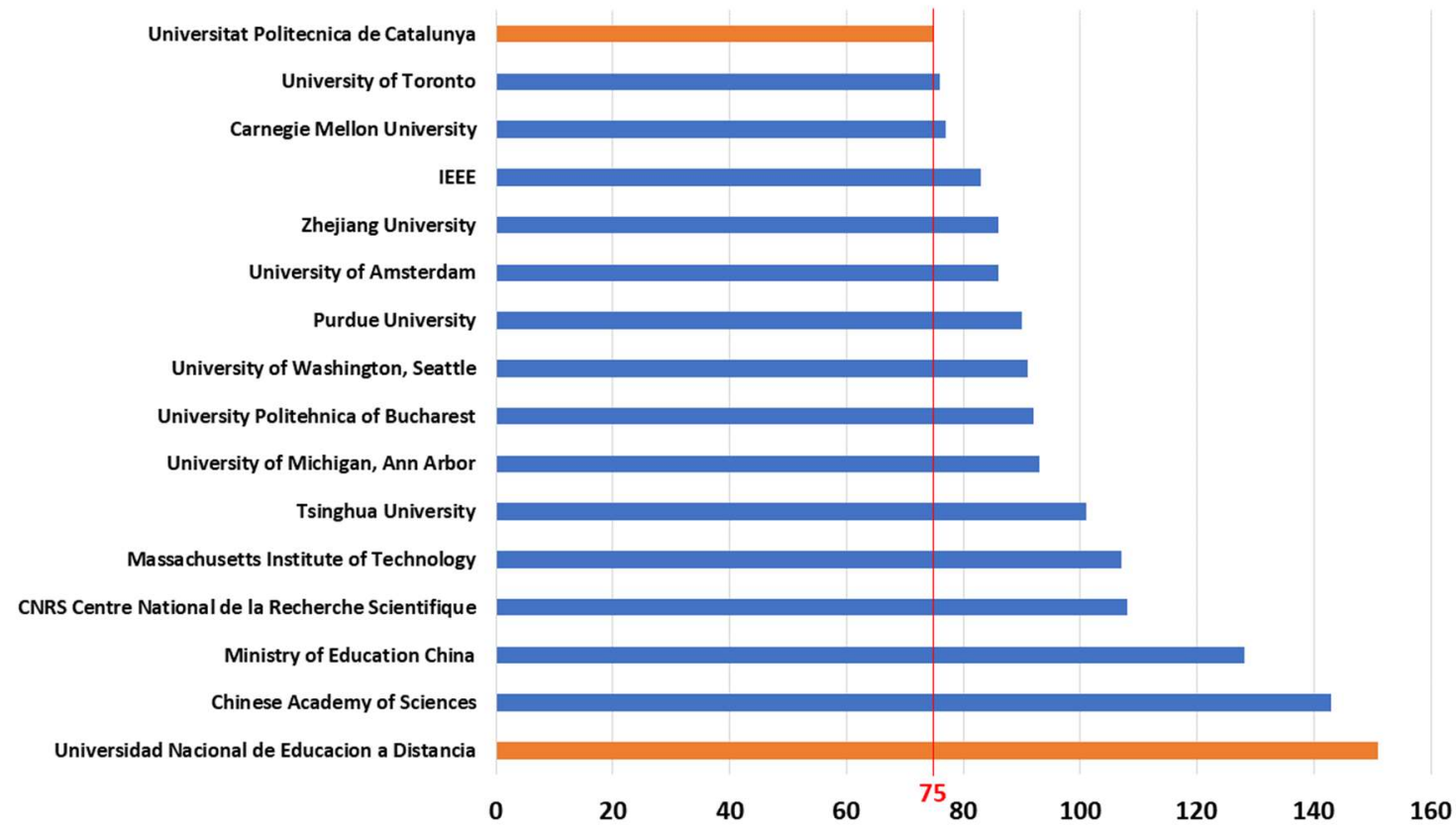

Figure 7. Main institutions related to virtual labs publications.

\subsection{Journals and Procedings Metric Analysis}

Another interesting point in bibliometric analysis in one specific topic is the qualitative analysis of is the journals and proceedings that publish in it. This can be done based on some parameters such as: h-index or item published. Some authors define the Thematic H-index (TH-index), which is based on calculating the H-index for a specific topic. This is usually useful to evaluate the impact of a given topic for a publication medium, either proceeding or journal [33].

The list of the top 10 Conference or Proceedings on virtual laboratories is listed in Table 2. Those that have at least 70 publications on this topic have been selected. These data were retrieved with special queries as: TITLE-ABS-KEY (virtual AND lab*) AND (LIMIT-TO (EXACTSRCTITLE, 
"IEEE Transactions on Instrumentation and Measurement")). It can be appreciated as the ranking by number of items published is: first, "Lecture Notes in Computer Science Including Subseries Lecture Notes in Artificial Intelligence and Lecture Notes in Bioinformatics", second "Proceedings of SPIE (International Society for Optics and Photonics)", and the third "ASEE Annual Conference and Exposition Conference Proceedings" (ASEE is the American Society for Engineering Education). Nevertheless, if now it is considered the TH-index then the above rank is different, where third place is now for "Studies in Health Technology and Informatics", formally a Book Series that are indexed as Proceedings by Scopus. This series was initiated to promote research conducted under the auspices of the bioengineering branch of the EC's (European Community) Advanced Informatics in Medicine (AIM) and Biomedical and Health Research (BHR) programs. One driving aspect of international health informatics is that telecommunication technology, rehabilitation technology, smart home technology and many other components are moving together and forming an integrated world of information and communication media.

Another very important aspect for researchers is the average citations received by a document $(\mathrm{TC} / \mathrm{N})$ in each source of publication. Thus, Table 2 shows a maximum of 7.7 for "Studies in Health Technology and Informatics" followed by 5.2 for the "Proceedings Frontiers in Education Conference (FIE)".

Table 2. Main bibliometric indicator for the top 10 conference or proceeding on virtual labs.

\begin{tabular}{|c|c|c|c|c|c|c|c|}
\hline Conference or Proceeding & Publisher & $\mathbf{N}$ & $\%$ & TH-Index * & $\begin{array}{l}\text { Total Citation } \\
\text { (TC) }\end{array}$ & $\mathrm{TC} / \mathrm{N}$ & $\mathbf{R}_{\mathrm{TC} / \mathrm{N}}$ \\
\hline $\begin{array}{l}\text { Lecture Notes in Computer Science } \\
\text { Including Subseries Lecture Notes in } \\
\text { Artificial Intelligence and Lecture } \\
\text { Notes in Bioinformatics }\end{array}$ & Springer & 537 & 10.54 & 20 & 2137 & 4.0 & 3 \\
\hline $\begin{array}{l}\text { Proceedings of SPIE: The International } \\
\text { Society for Optics and Photonics }\end{array}$ & $\begin{array}{l}\text { Society of Photo-optical } \\
\text { Instrumentation } \\
\text { Engineers }\end{array}$ & 418 & 8.20 & 12 & 812 & 1.9 & 4 \\
\hline $\begin{array}{l}\text { ASEE Annual Conference and } \\
\text { Exposition Conference Proceedings }\end{array}$ & $\begin{array}{l}\text { American Society for } \\
\text { Engineering Education }\end{array}$ & 293 & 5.68 & 9 & 424 & 1.4 & 6 \\
\hline Applied Mechanics and Materials & Scitec Publications Ltd. & 289 & 5.67 & 3 & 93 & 0.3 & 11 \\
\hline Advanced Materials Research & Trans Tech Publications & 215 & 4.22 & 3 & 91 & 0.4 & 10 \\
\hline $\begin{array}{l}\text { Proceedings Frontiers in Education } \\
\text { Conference (FIE) }\end{array}$ & IEEE Education Society & 125 & 2.45 & 11 & 654 & 5.2 & 2 \\
\hline $\begin{array}{l}\text { ACM International Conference } \\
\text { Proceeding Series }\end{array}$ & $\begin{array}{c}\text { Association for } \\
\text { Computer Machinery }\end{array}$ & 89 & 1.75 & 5 & 106 & 1.2 & 7 \\
\hline $\begin{array}{l}\text { IFAC Proceedings Volumes IFAC } \\
\text { Papers online }\end{array}$ & IFAC Secretariat & 89 & 1.75 & 6 & 162 & 1.8 & 5 \\
\hline AIP Conference Proceedings & $\begin{array}{l}\text { AIP (American Institute } \\
\text { of Physics) }\end{array}$ & 74 & 1.45 & 4 & 65 & 0.9 & 9 \\
\hline $\begin{array}{l}\text { Communications in Computer and } \\
\text { Information Science }\end{array}$ & Springer Verlag & 71 & 1.39 & 4 & 72 & 1.0 & 8 \\
\hline $\begin{array}{l}\text { Studies in Health Technology and } \\
\text { Informatics }\end{array}$ & IOS Press & 71 & 1.39 & 12 & 549 & 7.7 & 1 \\
\hline
\end{tabular}

N: Number of publications; TH-Index: H-index for this topic; TC: Total Citations; TC/N: Citations per document; $\mathrm{R}_{\mathrm{TC} / \mathrm{N}}$ : Rank by Total Citations per publication

If the above analyses are done for journals, Table 3 is obtained. In general, it is found that the first 10 journals have fewer publications than proceedings, but TH-index are larger, and they get more citations globally, also on citations' average per document (TC/N). The TH-Index of journal is led by the "IEEE Transactions on Education" with 26 followed by "IEEE Transactions on Instrumentation and Measurement" with 21, both from the IEEE. For the first journal, the scope covers educational methods, educational technology, teaching materials, history of science and technology, and educational and professional development, as well as programs in electrical engineering, computer engineering, and related disciplines. In addition, for the second journal, the scope is focused on innovative solutions to the development and use of electrical and electronic instruments and equipment to 
measure, monitor and/or record physical phenomena for advancing measurement science, methods, functionality and applications, and one of the topics is the practice of measurement.

Regarding the citations average per document $(\mathrm{TC} / \mathrm{N})$, it can be observed that the maximum is than 26.9 for "Chinese Journal of Scientific Instrument" followed by "Transactions of the Chinese Society of Agricultural Engineering" with 20.2, both journals from China. Although dedicated to instrumentation and agricultural engineering respectively, they also include innovative educational applications such as virtual laboratories.

Table 3. Main bibliometric indicator for the top 10 journals on virtual labs.

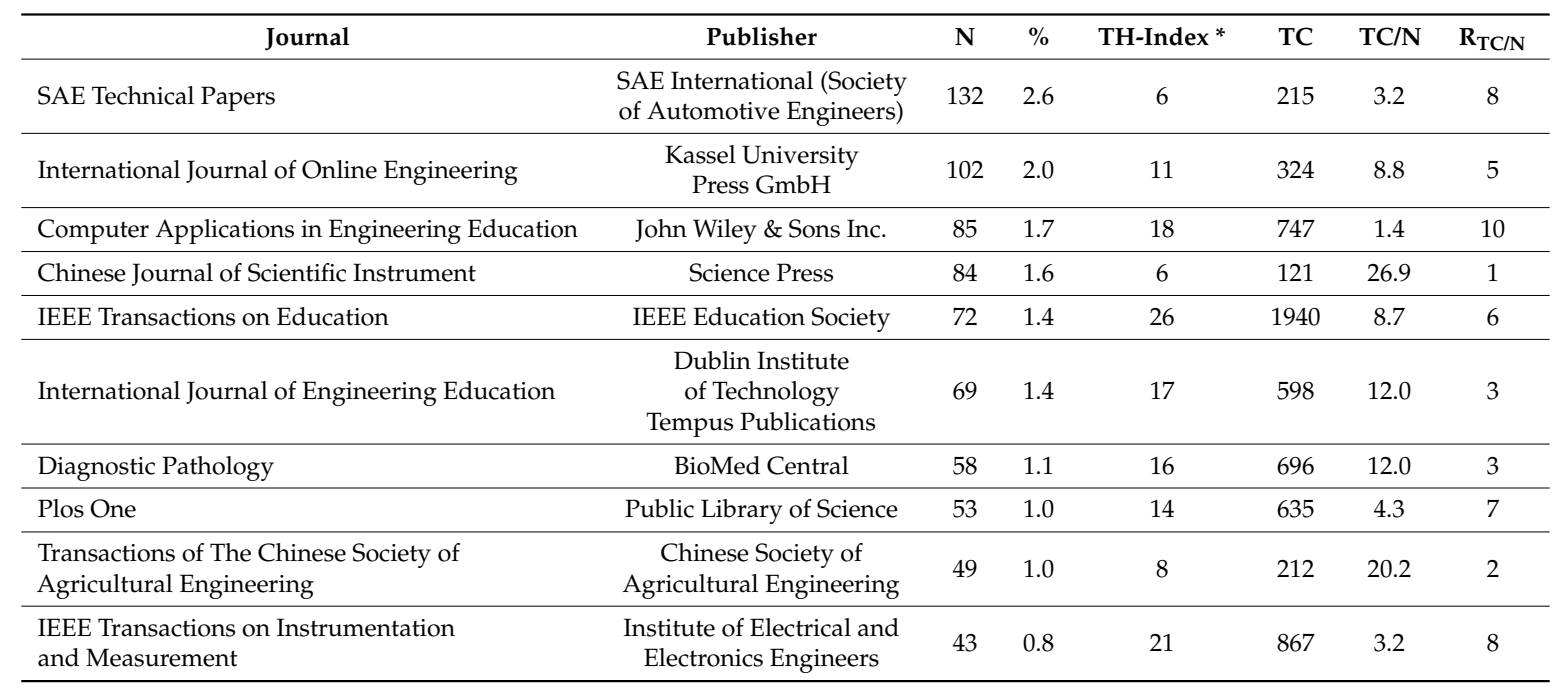

$\mathrm{N}$ : Number of publications; TH-Index: H-index for this topic; TC: Total Citations; TC/N: Citations per document;

$\mathrm{R}_{\mathrm{TC} / \mathrm{N}}$ : Rank by Total Citations per publication

\section{The Case Study: Spanish Universities}

Considering the countries that publish about virtual laboratories, to study a specific case, inclusion are criteria of those representing more than $1 \%$ of total scientific production and, among them, the one that is closest to the mean will be selected. As shown in Figure 8, those representing more than $1 \%$ give us the top 20, and among them the average has been made, which gives a mean value of $4.1 \%$, the value of Spain. In addition, the selection of this country as a case study is especially interesting because it has the institution that most publishes in relation to this topic.

The University must contribute to the advancement of society and knowledge and must therefore respond to the demands and needs of the society in which it is situated [34]. In this sense, the statistics for Spain are good, since there are 1.8 universities per million inhabitants, and if the age range is between 18-24 years, the university age, the figure rises to 26.5 universities per million inhabitants [35]. In Spain, the first university was the University of Salamanca, founded in 1218, and this year is the eighth centenary of its foundation. There are currently 84 universities in Spain, of which 50 are public and 34 privates [35]. Among the public universities, 17 offer the possibility of online careers and virtual courses, while, in the private ones, all offer them. Only six virtual or online learning universities as such are registered: Universidad a Distancia de Madrid (UDIMA), Universidad Nacional de Educación a Distancia (UNED), Universidad Internacional de la Rioja, Universidad Isabel I de Castilla, Universitat Internacional Valenciana (VIU), and Universitat Oberta de Catalunya. Of these, the only public one is the National University of Distance Education (UNED), which was founded in 1972.

Distance learning is not new, and neither are the methodologies associated with it. The biggest drawbacks have been the science and engineering careers with the practical classes. According to recent studies, at least one in three university students will have completed an online course in 2012, and $95 \%$ of them are expected to do so by 2020 [36]. 


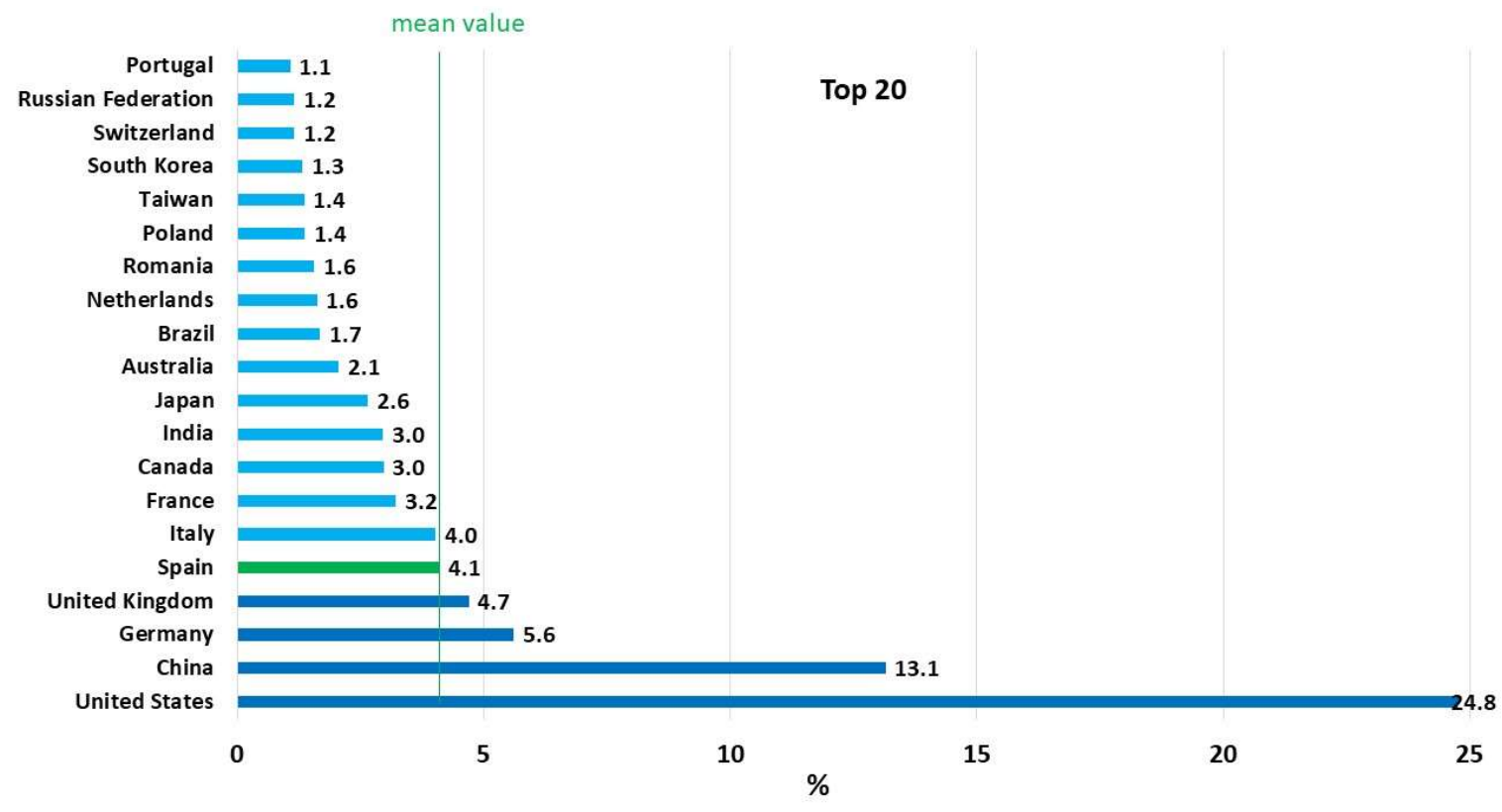

Figure 8. Top 20 countries on virtual lab publications.

\subsection{Trend over Time and Types of Publications in Spanish Universities}

In this second search, filtering with affiliation country Spain, a total of 946 results of work related to virtual laboratories have been obtained in the Scopus database in the period 1984 to 2017. Therefore, the Spanish publications related to virtual laboratories indexed in Scopus began in 1984, and since then they have had an upward trend as can be seen in their trend line in Figure 9. In 2007, there was a decrease, but since then they have been growing until reaching more than 80 publications in 2011 and since then this level has been maintained with small fluctuations.

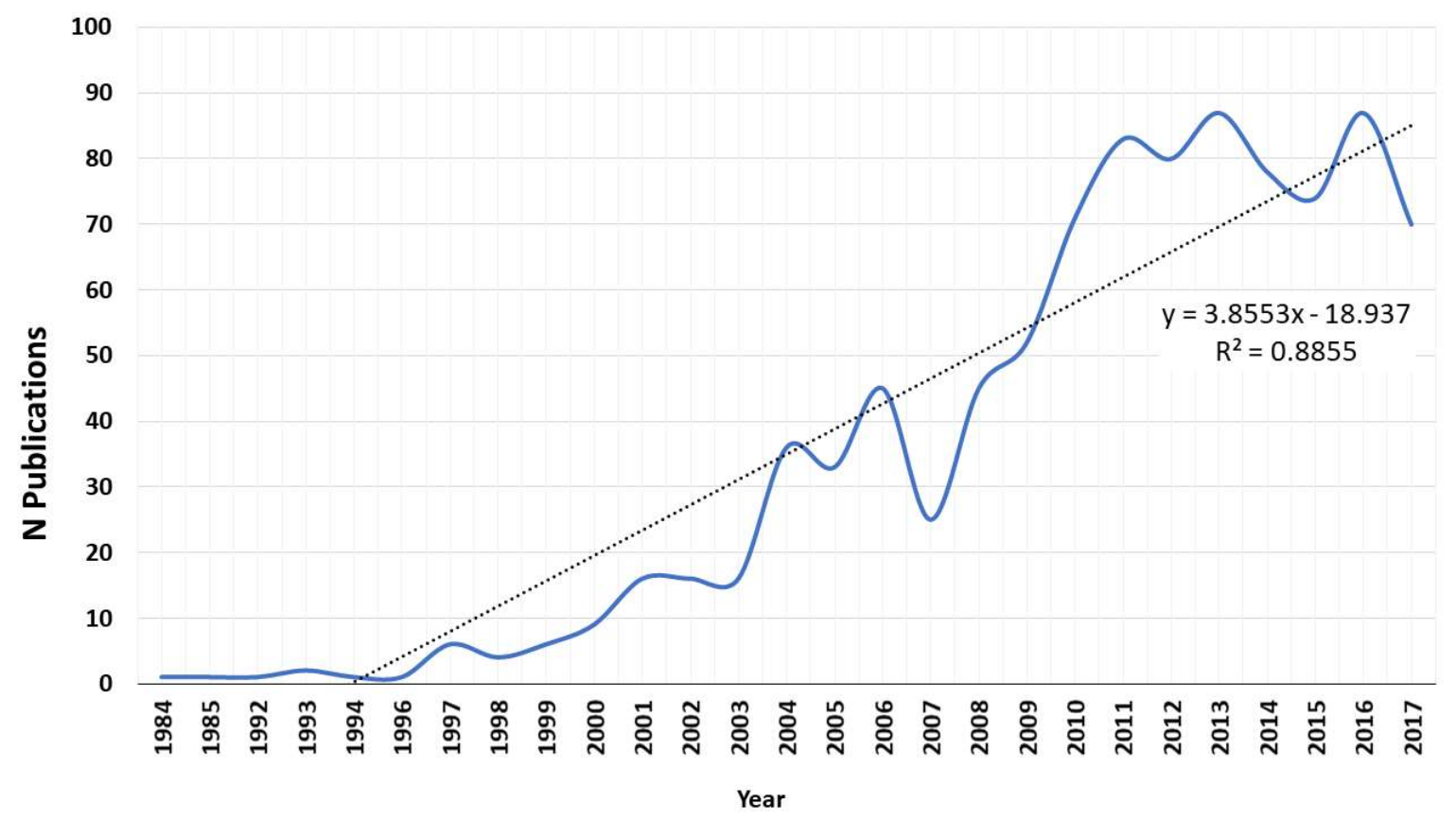

Figure 9. Time evolution of Spanish publications in virtual laboratories

In terms of the type of document published, it has been observed that 51\% (481) are articles in journals, and to these we could add a further $3 \%(29)$ if we add the review articles. Conference papers account for $44 \%$ (415), while books or book chapters account for only $2 \%$. These data indicate the 
maturity of the topic in Spain, since, when the topics are very novel, in percentage of publications in congresses, it exceeds the articles in the journal [33].

\subsection{Affiliation and Its International Collaboration}

Figure 10 shows Spanish universities with more than 10 publications in virtual laboratories. As expected, they are led by the UNED, given the online learning nature of this public university. This ranking is followed by the three major polytechnic universities in Spain: Madrid, Catalonia and Valencia. Furthermore, it is noteworthy that, among the private universities, there are only two in this ranking, Universidad de Deusto and Universitat Oberta de Catalunya, although it should also be noted that private universities in Spain do not stand out for their scientific production.

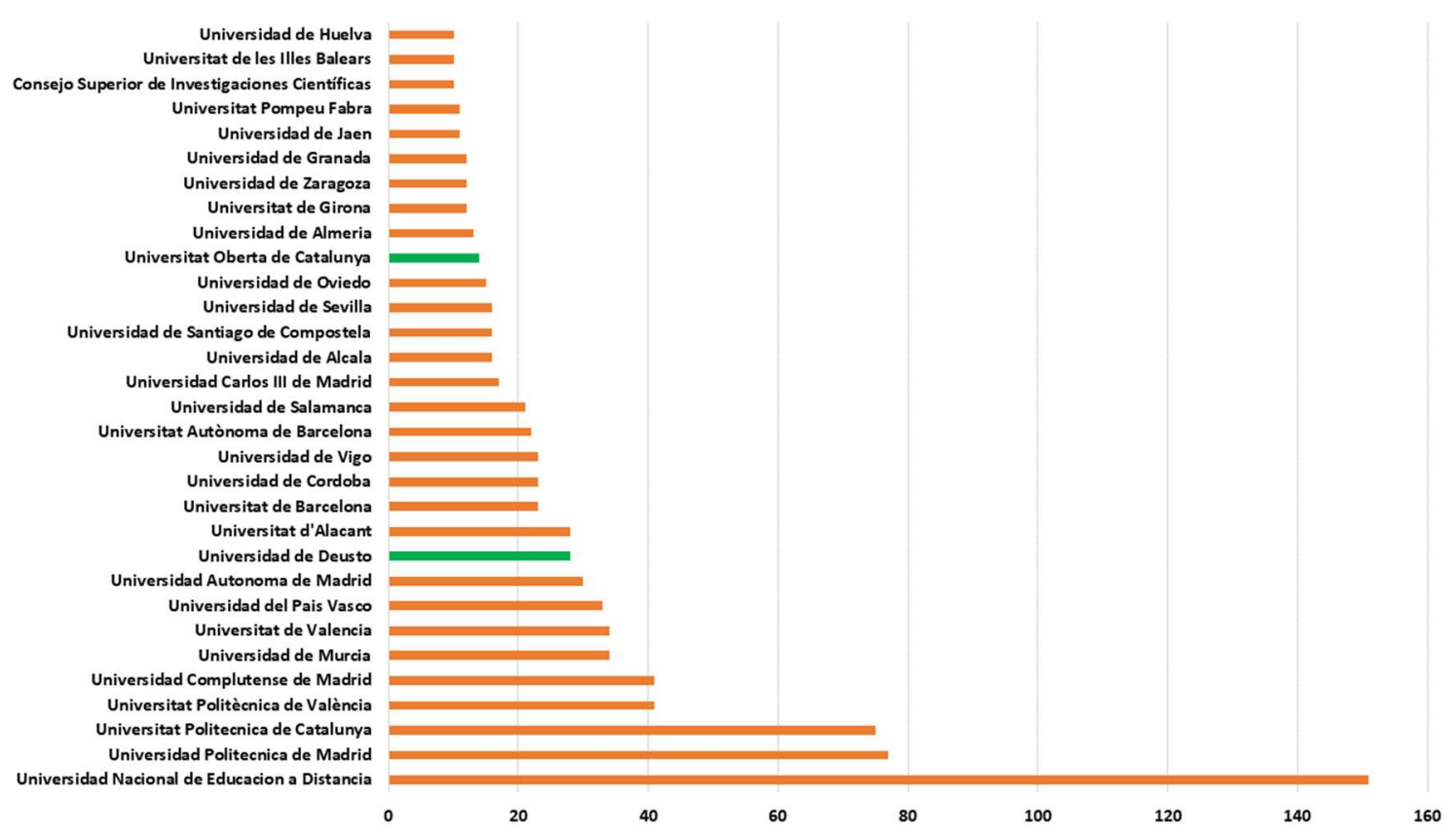

Figure 10. Spanish universities with more than 10 publications in virtual laboratories.

These publications have had a high rate of international collaboration, as more than $54 \%$ of them are co-authored with a foreign country. It should be noted that other studies indicate that, when there is international collaboration, the rate of citations is higher than when there is no collaboration [30].

International collaboration is led by the USA in $10.5 \%$ of cases, followed by the UK in $9.4 \%$. Afterwards, it is observed how it is marked by countries of the environment such as 3rd Italy (8\%), 4th France (6\%), 5th Germany (6\%), and 6th Portugal (4\%). However, with countries with which language is shared, collaborations are much weaker, Chile in 12th place $(2.7 \%)$ and Cuba in 15th place $(2.5 \%)$.

Figure 11 shows the international collaboration of Spanish publications. Those countries where there is no scientific collaboration in this regard have been represented in blue, which as can be seen is basically Africa except for northern countries such as Morocco, Tunisia, and Egypt, although the collaboration is symbolic and much of Asia. Although research is being carried out on scientific publications, the results are probably related to the educational model and therefore Spanish scientific collaboration is centred on European countries and the USA—on the one hand, and, to a lesser extent on Latin American countries, on the other. 


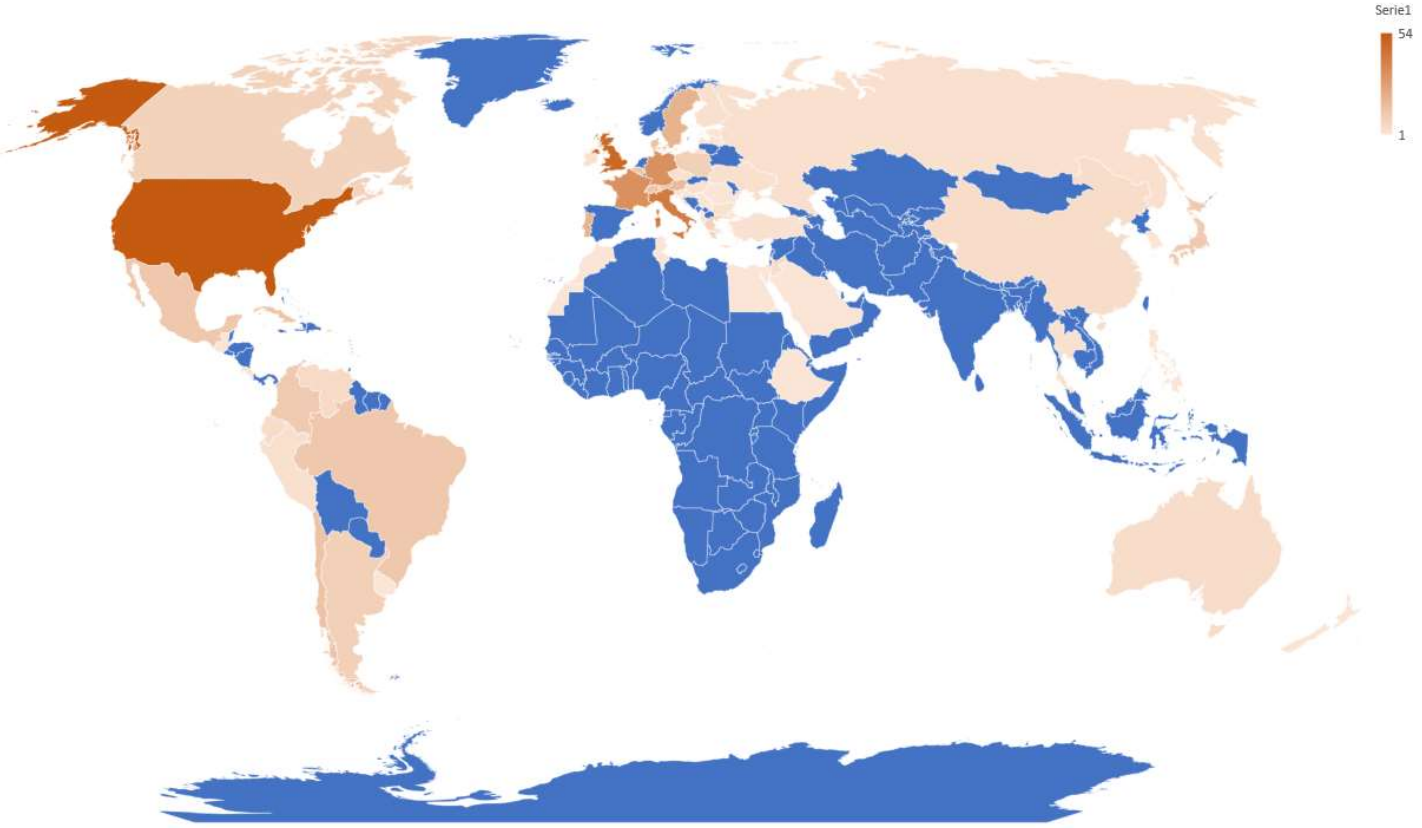

Figure 11. International collaboration of Spanish publications (blue means no collaboration).

\subsection{Subject Categories}

The thematic categories in which these works are classified are offered directly by the Scopus database and it should be noted that there may be overlaps, since a work may be assigned to more than one category. Figure 12 shows the different subject categories. It can be seen that it is dominated by the Engineering category with $26 \%$, followed by the Computer Science with $23 \%$. Then, with these two categories, there would be around $50 \%$ of them, as was the case on the global international scene. However, it is interesting to note that there is also a significant percentage within the social sciences with $17 \%$, more than twice as high as on the international scene ( $8 \%)$. It should be noted that there are many other categories where this type of work was similar, indicating its multidisciplinary nature and how it is a question of training that can be used by many different branches of science [37]. For example, see: Mathematics; Physics and Astronomy; Medicine; Biochemistry, Genetics and Molecular Biology; Materials Science, Chemistry, Psychology, Environmental Science or Agriculture.

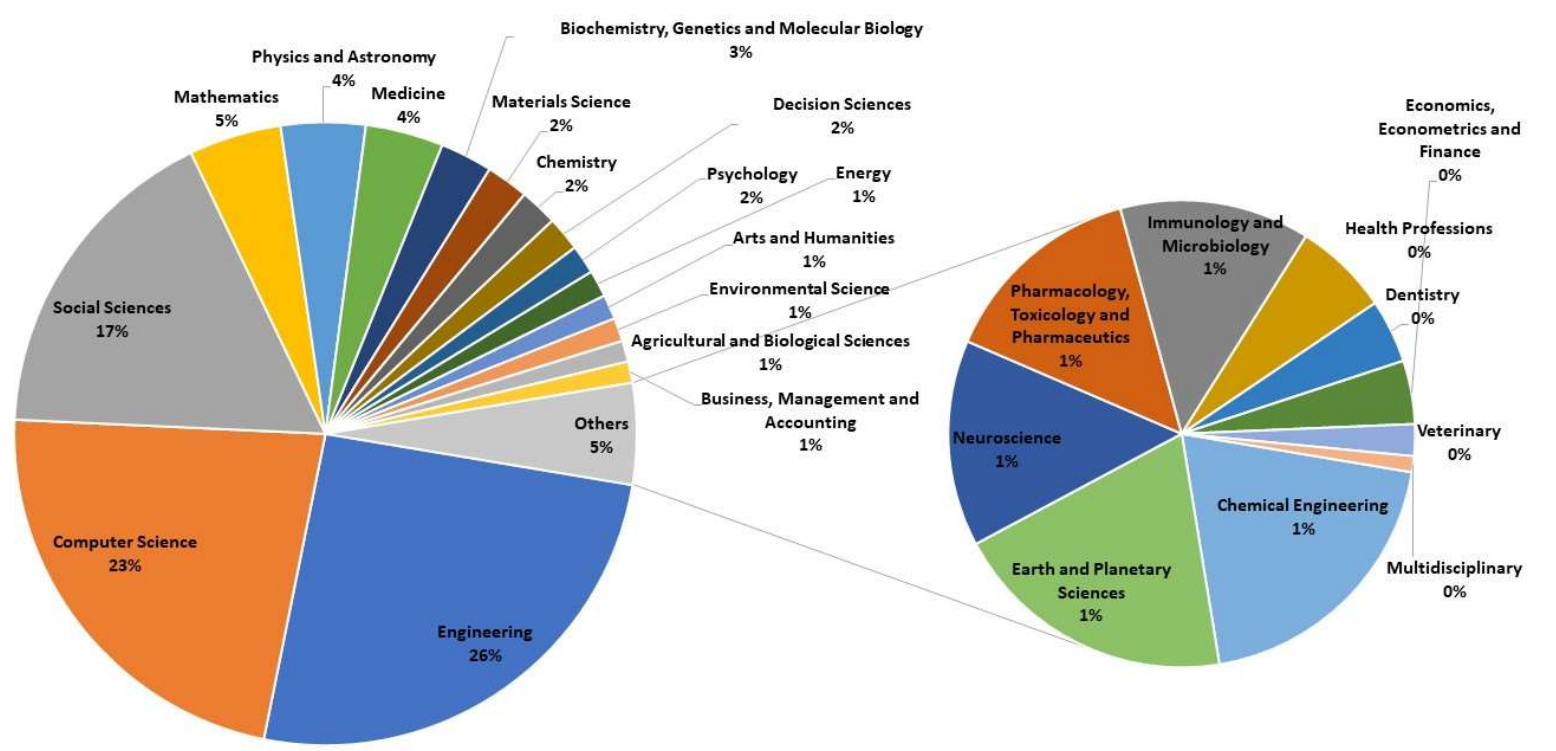

Figure 12. Distribution in thematic categories of the Spanish publications on virtual laboratories. 
These results are in line with the institutions that have the greatest scientific production, especially highlighting the role of Spanish polytechnic universities, makes the engineering category have this dominant place. Since, to the general advantages of the method, they could highlight the more specific ones of the engineering are: that one experiments without risk, that one cannot damage any equipment while one learns the handling of these, and one does not use laboratory material. Then, there is the added benefit of security and access to large equipment.

\subsection{Keywords}

The study of the set of keywords of a specific topic allows us to analyze what are the specific issues [38]. With the keywords of all the analyzed publications, a cloud word has been created to obtain Figure 13, where it can be seen that they are led by: virtual reality, students, education, distance education, e-learning, teaching and engineering education. However, in Table 4, the most frequent keywords are presented in these publications. It can be observed that the Java programming language appears in prominent positions.

Table 4. Main keywords of Spanish publications on virtual laboratories.

\begin{tabular}{|c|c|}
\hline Keyword & $\mathbf{N}$ \\
\hline Virtual Reality & 217 \\
\hline Students & 154 \\
\hline Distance Education & 147 \\
\hline Education & 141 \\
\hline E-learning & 134 \\
\hline Engineering Education & 131 \\
\hline Teaching & 129 \\
\hline Remote Laboratories & 113 \\
\hline Virtual Laboratory & 90 \\
\hline Article & 86 \\
\hline Human & 86 \\
\hline Computer Simulation & 81 \\
\hline Computer Software & 76 \\
\hline Humans & 70 \\
\hline Internet & 61 \\
\hline Virtual Lab & 49 \\
\hline User Interfaces & 48 \\
\hline Priority Journal & 45 \\
\hline Automation & 43 \\
\hline Computer Aided Instruction & 43 \\
\hline Experiments & 43 \\
\hline Java Programming Language & 42 \\
\hline Remote Laboratory & 39 \\
\hline Simulation & 39 \\
\hline Algorithms & 38 \\
\hline Control Education & 38 \\
\hline Education Computing & 35 \\
\hline Curricula & 34 \\
\hline Female & 32 \\
\hline Learning Management System & 32 \\
\hline Remote Labs & 32 \\
\hline World Wide Web & 31 \\
\hline
\end{tabular}




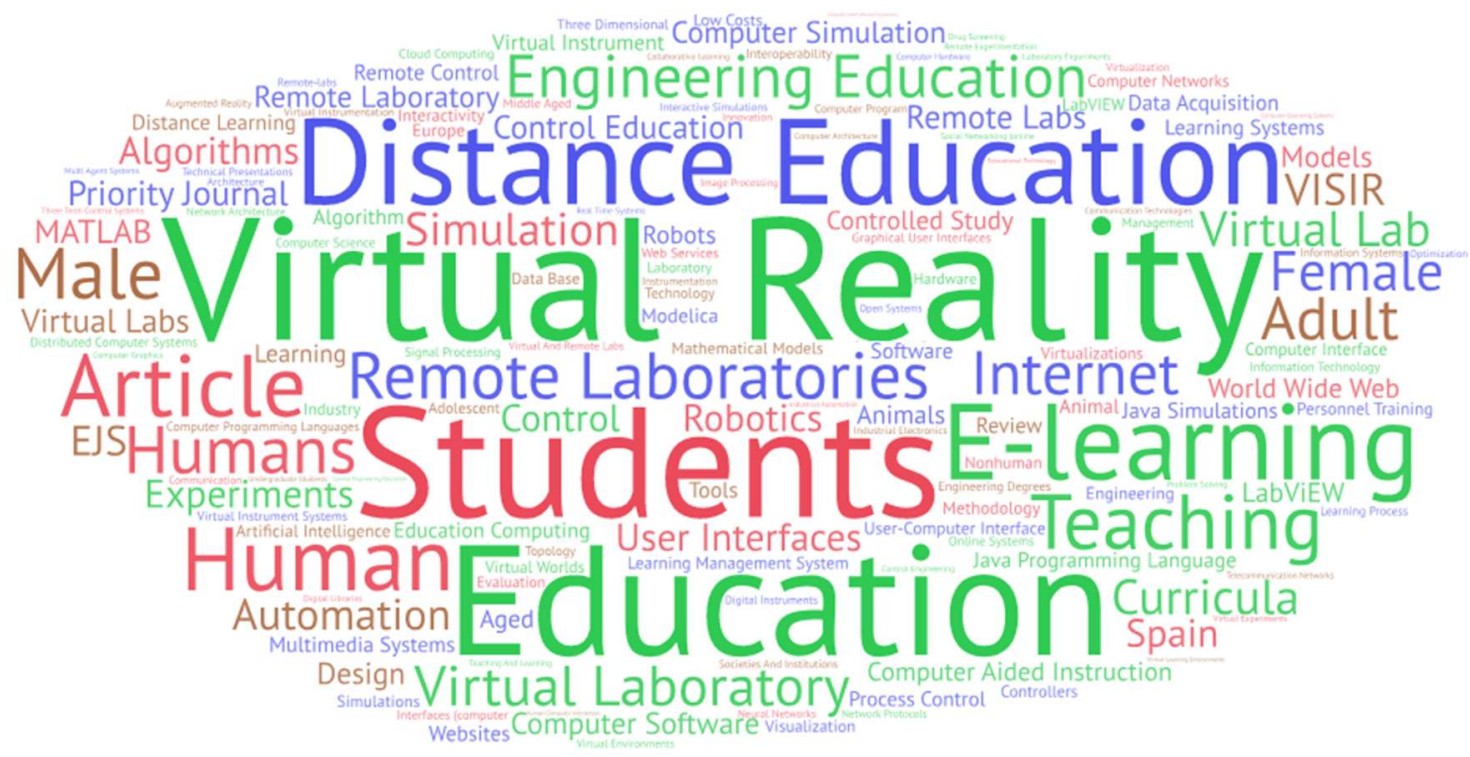

Figure 13. Cloud word of the main keywords of Spanish publications on virtual laboratories.

Table 5 analyses these keywords for the top ten Spanish institutions, highlighting their three main keywords. The UNED stands out for its distance education and engineering education, while the three polytechnic universities use virtual reality, and only the Polytechnic of Madrid does so in engineering education. The keywords associated with the students also play an important role, since they are the destiny of the virtual laboratories, and the perception of them is essential in this type of research [39]. The case of the University of Murcia stands out because it is highly focused on programming languages and software, more closely related to computer research, or the case of the University of Valencia, which focuses on the human aspect, seeking a more social perspective, as it also focuses on virtual teams. With respect to university students, the issue of virtual laboratories could have the great disadvantage of eliminating teamwork, which is one of the cross-cutting skills most in demand for university students $[40,41]$. The University of Deusto, the only private university that appears in this ranking, introduces the terms virtual instrumentation and e-learning, the latter being a term that is generally less commonly used in distance education (see Table 5). If both terms are analysed, the number of works are quite similar, and the dates of publication are close, since "distance education" begins in 2002 and "e-learning" in 2004. For example, the 147 "distance education" publications have been cited 1045 times while the 134 e-learning publications have been cited 724 times. This means that the "distance education" have been cited on average 7.1 times compared to 5.2 times for e-learning.

Table 5. Main keywords of the top-10 Spanish universities in virtual laboratories.

\begin{tabular}{lccc}
\hline \multicolumn{1}{c}{ University } & $\mathbf{1}$ & $\mathbf{2}$ & $\mathbf{3}$ \\
\hline Universidad Nacional de Educación a Distancia & Distance Education & Remote Laboratories & Engineering Education \\
\hline Universitat Politecnica de Catalunya & Virtual Reality & Computer Simulation & Students \\
\hline Universidad Politécnica de Madrid & Virtual Reality & Engineering Education & Students \\
\hline Universitat Politècnica de València & Virtual Reality & Distance Education & Education \\
\hline Universidad Complutense de Madrid & Students & Virtual Reality & Distance Education \\
\hline Universidad de Murcia & Java Programming & Computer Software & Distance Education \\
\hline Universitat de Valencia & Human & Virtual Reality & Virtual Teams \\
\hline Universidad Autónoma de Madrid & Virtual Reality & Distance Education & Education \\
\hline Universidad de Deusto & Remote Laboratories & Virtual Instrument & Systems \\
\hline Universitat d'Alacant & E-learning & Students & Esearning \\
\hline
\end{tabular}


The community or cluster detection in networks is a very useful tool in bibliometric studies [42,43]. Thus, communities or clusters are generally groups of nodes that are more likely to be connected to each other than to members of other groups or to the rest of the network [44]. The analysis of communities carried out with VOSviewer SW allows for graphically displaying the relationships between them and to export these images [26]. If we apply the community detection technique to the set of keywords obtained (see Figure 14), it can be seen that the nodes that appear most frequently are the largest and the thickness of the link indicates the greater or lesser relationship between them. Figure 14 shows seven clusters obtained from the analysis, and Table 6 summarizes their characteristics. For each cluster, a name has been proposed to facilitate identification. It groups a series of main terms or key words as highlighted in Figure 14. The main cluster, red colour, was named Virtual reality. It involves the research of virtual laboratories that apply these technologies. A second cluster in red in Figure 14, which is characterized by its distance from the core, is the one that focuses on the type of user, and its characterization is by gender or age. The third cluster is focused on e-learning terms, and how virtual laboratories affect this type of teaching. The fourth cluster, which is yellow in Figure 14, is dedicated to computing as programming languages and also includes three types of teaching or industry to which they are oriented: computing education, biomedical engineering, and electronics industry. The fifth cluster, purple in Figure 14, is focused on automation, process control, and robots. The sixth cluster is dedicated to computer simulation, computer software, modelica language, and object oriented modeling. See the sky blue colour in Figure 14. Finally, the orange cluster in Figure 14, focused on engineering education, highlights keywords such as remote laboratories, learning management systems, virtual instrument systems, or augmented reality.

Figure 15 shows the evolution of the set of keywords within the communities detected. The period in which the greatest differences are observed, from 2008 to 2014, has been selected. In the early years (2008), there were publications with keywords such as: internet, world wide web, or computer simulation. Then, in 2011, they started e-learning or teaching and to reach virtual instrument system, automatic evaluation, online experiments, augmented reality, control engineering education or VISIR in 2014. The latter term, VISIR, refers to an open source software for virtual analog electronic laboratories in which seven universities participate around the world and, specifically in Spain, the UNED [45].

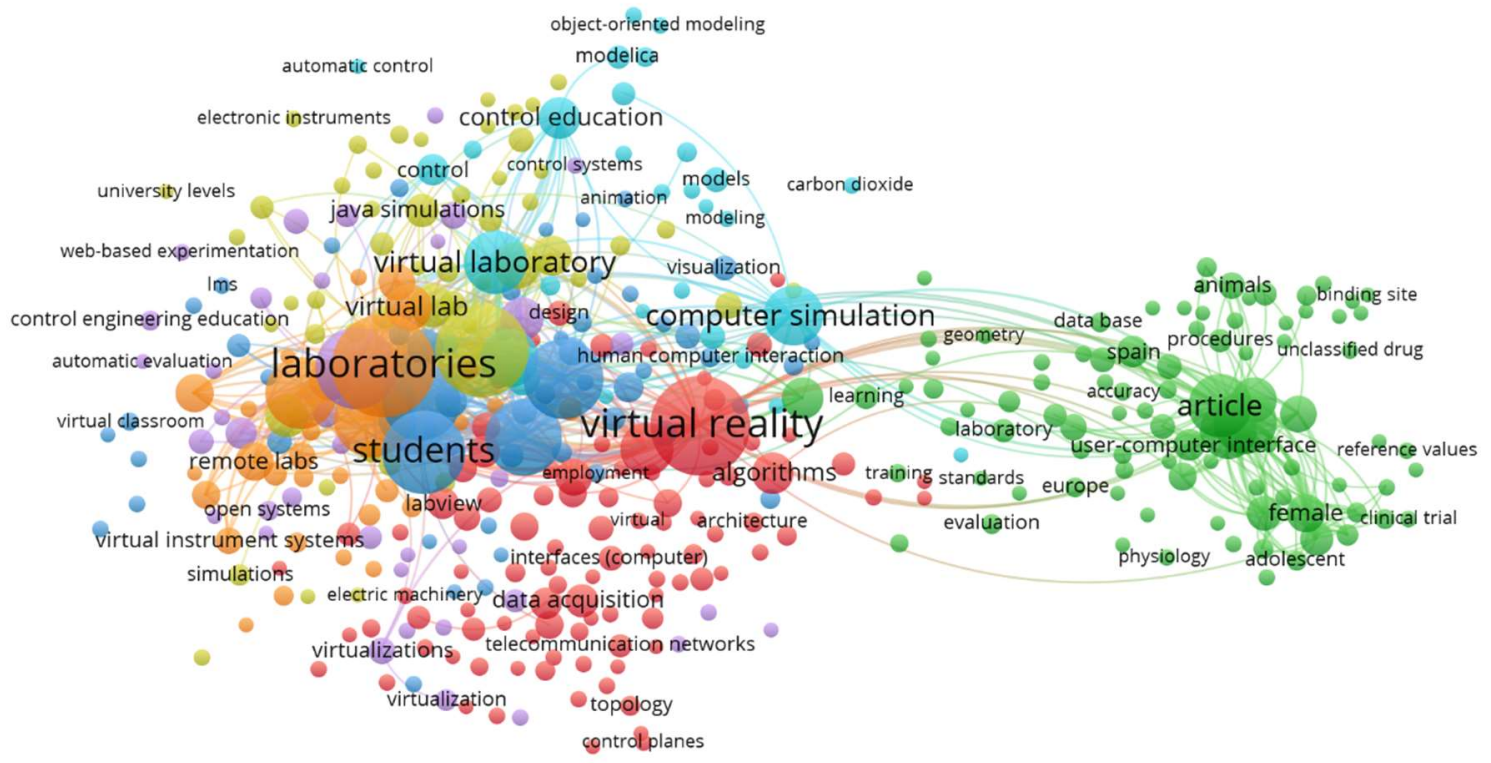

Figure 14. Communities related to publications on virtual laboratories in Spain. 
Table 6. Spanish clusters or communities related to publications on virtual laboratories.

\begin{tabular}{cllcc}
\hline Cluster & Color & \multicolumn{1}{c}{ Keywords } & N & Proposed Name \\
\hline 1 & Red & $\begin{array}{l}\text { Virtual reality, algorithms, internet, } \\
\text { world wide web, data acquisition }\end{array}$ & 97 & Virtual reality \\
\hline 2 & Green & $\begin{array}{l}\text { Human, humans, user computer } \\
\text { interface, male, female }\end{array}$ & 92 & Users \\
\hline 3 & Blue & $\begin{array}{l}\text { E-learning, students, teaching, } \\
\text { computer aided instruction, } \\
\text { curricula, virtual learning } \\
\text { environments }\end{array}$ & 57 & E-learning \\
\hline 4 & Yellow & $\begin{array}{l}\text { Education computing, experiments, } \\
\text { java programming language, } \\
\text { biomedical engineering, electronics } \\
\text { industry }\end{array}$ & 52 & Computer science \\
\hline 5 & Purple & $\begin{array}{l}\text { Distance education, automation, } \\
\text { process control, robots }\end{array}$ & 41 & Automatic and robotics \\
\hline 7 & Sky Blue & $\begin{array}{l}\text { Computer simulation, computer } \\
\text { software, modelica language, object } \\
\text { oriented modelling }\end{array}$ & 30 & Computer simulation \\
\hline & Orange & $\begin{array}{l}\text { Engineering Education, remote } \\
\text { laboratories, learning management } \\
\text { systems, virtual instrument systems, } \\
\text { augmented reality }\end{array}$ & 30 & Engineering Education \\
\hline
\end{tabular}

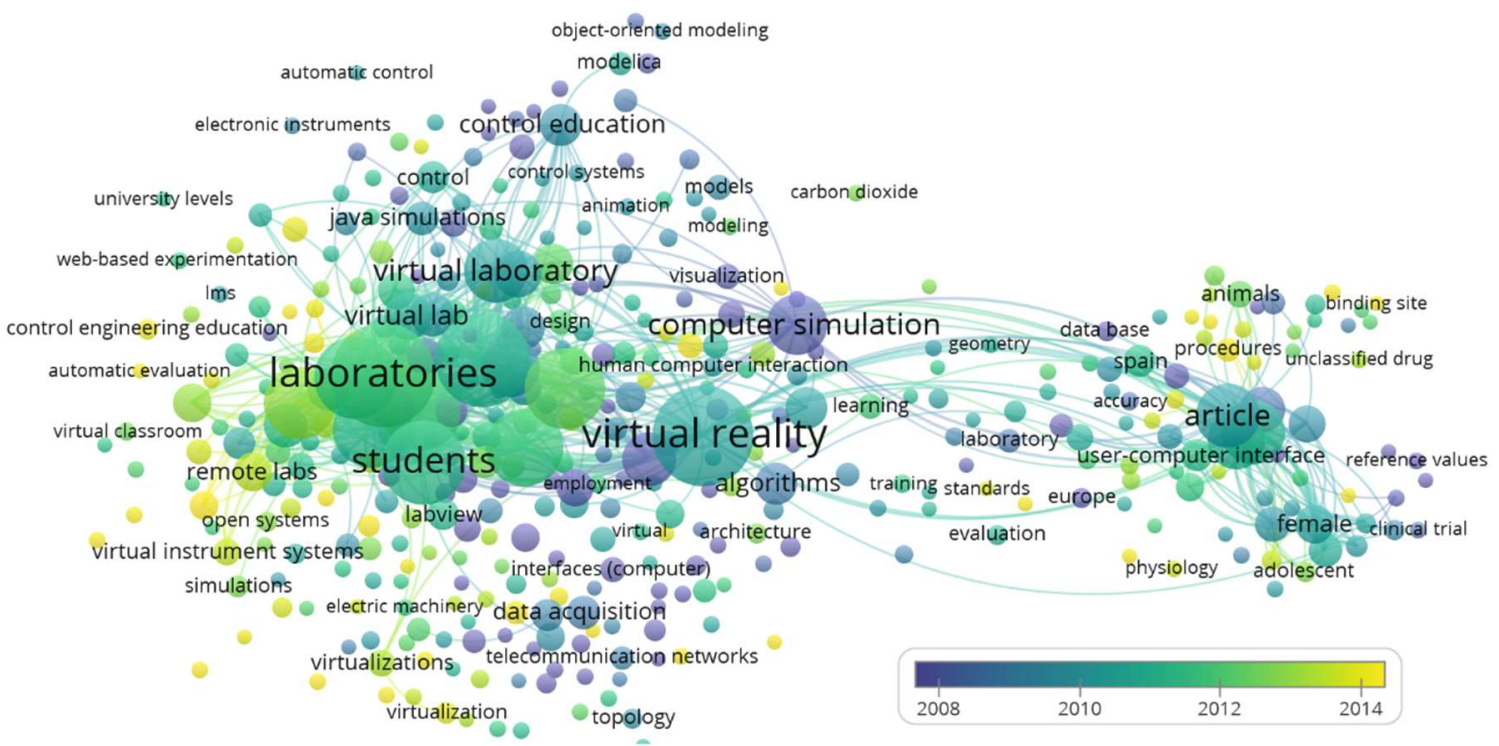

Figure 15. Temporal evolution of keywords in relation to Spanish publications on virtual laboratories.

\section{Discussion}

One of the most attractive e-learning applications for higher education is the virtual laboratory, which provides students with the chance to put into practice their newly acquired knowledge and skills by giving them limitless use of the Internet [8]. It has been noted that the overall trends in research on virtual laboratories at the global level and in the case of study have followed an upward trend and have stabilized in good publication ratios in recent years. The subject categories worldwide and in the case of study are distributed in the same way, highlighting Engineering, Computer Science and a huge range of categories that illustrate the multidisciplinary nature of the subject and the great application to many disciplines. 
In the case study, certain lines of research detected by the different communities or clusters have been obtained (Table 6). It is noteworthy that the most expected, Engineering Education, Computer Simulation, Automatic and Robotics or even Programming, are not the largest communities. In addition, this is even though the most productive institutions are the polytechnic universities, where engineering degrees are taught.

The new technologies and in particular the virtual laboratories, in relation to teaching, indicate two possible ways forward, at least in the case study. On the one hand, how these developments in computing will affect the teaching and, on the other, the effect that these developments will have on the creation of new intercommunication models [46]. The large clusters have been in order: virtual reality, users and e-learning, as can be seen in all of them of a general and multidisciplinary nature within teaching. Virtual reality seems logical given what is being analyzed, since the student's immersion should be as high as possible in the laboratory to make the practice as similar as possible to reality [47]. It should be noted that this research shows that, within virtual laboratories, one of the main lines of research is that of virtual reality. The second aspect, the issue of users, has proved to be particularly gratifying, since there is a great deal of dedication to this issue, in terms of how one learns with this type of tool according to the nature of the population, such as gender [48] or age [49]. Teaching technologies should be assessed for effectiveness and satisfaction [50], as there is a risk of thinking that they are the solution in themselves, such as the master classes that have been "innovated" with Power Point sessions that have not shown great effectiveness in learning [51].

It is in this last aspect where virtual laboratories can play a great role, as they are a good complement to teaching [52]. For the time being, the focus is rather on engineering [53] and, to a lesser extent on science careers [54], which can even support real laboratory experiences. However, to improve its usefulness, it is necessary to select the contents and objectives to be achieved. In this way, it will be possible to make a suitable design of the activity in which they are integrated and produce positive effects in the students' learning. As an added advantage of the virtual laboratory, if it is well conceived, it can serve as a tool for the professional future of graduates. For instance, see the "Electronic Atlas of Parasitology" (http://www.ufrgs.br/para-site/) of the Federal University of Rio Grande do Sul (Brazil), where apart from being a virtual laboratory of parasitology, it has an online collection of parasites to be accessed in open access.

The student-centred teaching model is focused on students engaged in learning skills of a high order [8]. The proximity of team members has potentially important implications for the collaborative teams' work [55]. Thus, some research suggests in their results that virtual team performance is strongly affected by the quality of teamwork [56]. One of the most worrying aspects is perhaps the possible loss of collaboration among students, teamwork skill [57]. Although there are studies that indicate that it is precisely in the traditional laboratory that this competence is very limited, and that students' perception of virtual laboratories as a means of teaching and of learning outcomes is very positive [48]. The use of the Internet for these educational purposes, virtual laboratories, can remove physical barriers to cooperative learning in teamwork [8]. This is generally associated with the possibility of iterative experimentation [58], which, as mentioned in the Introduction, was one of the advantages of virtual laboratories where there is no limit to opportunities. Undoubtedly, another of the great opportunities presented by virtual laboratories is the possibility of local access [59]. Undoubtedly, another of the great opportunities presented by virtual laboratories is the possibility of double access [46], for example, in computer classrooms for face-to-face learning with the presence of the teacher or in remote access from any point for distance learning.

This allows a design for the student's work with a continuity to continue exploring possibilities or even become familiar with the practice before going to class, which has been very positive in the introduction of technological tools in laboratory practices [39].

Sustainability, maintenance and outreach are very critical issues for the universities. Therefore, the first aspect, the sustainability of their resources, is one of the key points of the university survival, and they strongly depend on the number of students that can enroll in them. In technological 
careers, one of the major shortcomings is the university students' practices due to the costs of the laboratories. Virtual laboratories have demonstrated in several studies that they are useful tools and, in some cases, even better than traditional ones, since they allow a greater number of repeat experiments [59]. This certainly enables more students to be reached and therefore contributes directly to the sustainability of universities. In addition, virtual laboratories demand less maintenance than traditional ones, which also makes them more sustainable. Finally, from the point of view of outreach, virtual laboratories can reach a larger number of students, as they do not need to have a presence. As new generations are becoming acquainted with the early use of ICTs, VLs would appear to be widespread in the coming years and would be dominated by laboratory experimentation in regular education, from high schools to postgraduate curricula [60]. To achieve the long-term sustainability of universities, specialization strategies are required to attract students, as well as investments in the degrees offered by universities. Virtual laboratories have become a real fact in recent years not only at technical universities [61], but also at all types of university degrees. Because learners' and teachers' use of ICT along with the content provided by a virtual laboratory are key points in extending the system [62], and therefore the virtual laboratories are certainly a means to support the sustainability of universities.

\section{Conclusions}

Worldwide research on virtual laboratories has followed an upward trend in recent years that, since 1990, has been a linear upward trend, and, since 2011, it has stabilized at around 1400 publications per year. In the case of study, Spain, two periods have been observed, until 2007 and from 2008 onwards. The world's scientific production is mainly as conference papers, while, in Spain, it is in articles in journals, which indicates that it is a scientifically consolidated subject in Spain, as opposed to being something newer than the world level, although it should be noted that the differences are not remarkable.

Regarding the institutions, the world ranking by scientific production is led by a Spanish university, although according to a ranking by index of citations per article, the first three institutions are from the USA (Massachusetts Institute of Technology (MIT), University of Washington (Seattle), and IEEE). If this ranking takes into account the resources available, as the ratio of students per academic Staff, it is observed that the most productive institution is again the Spanish Universidad Nacional de Educacion a Distancia, followed by University of Toronto (Canada) and after University Politehnica of Bucharest (Romania).

About Spanish universities, the ranking of publications on virtual laboratories is led by the Universidad de Educación a Distancia (UNED) followed by the polytechnic universities of Madrid, Catalonia and Valencia. On the other hand, despite the high number of private universities in Spain which all offer virtual teaching, only one of them is in the ranking of virtual laboratories, the University of Deusto in the 10th place. These works have had a high rate of international collaboration, since more than $54 \%$ of them are co-authored with a foreign author, generally from the USA or European countries, and, at a much lower average from Latin American countries despite sharing the native language.

The subject categories are dominated by engineering followed by computer science, although it is noticeable in the large number of categories involved, and therefore one could conclude that it is something emerging and transversal in teaching. In relation to the social sciences, there is a high percentage, probably in the studies related to the social aspect and learning according to the students' characteristics.

For the case of the study, seven communities or clusters have been detected around which these publications are grouped, in the following order of importance: Virtual Reality, Users, E-learning, Programming, Automatic-Robotics, Computer Simulation and Engineering Education.

Given that the main categories are multidisciplinary in focus, it can be concluded that research in relation to virtual laboratories is being implemented as a model of teaching and learning with a great future within the university worldwide, and, in the case of study, the Spanish university. This is 
especially in university careers in engineering and science, but that, in the near future, may be extended to the other disciplines.

As a main conclusion, the possibility of virtual laboratories opens new perspectives for higher education sustainability, where the educational policies of countries must be reoriented, and the contents regularly reviewed so that university students are always able to respond to the requirements of the global world where we live.

Author Contributions: E.S.-M. and F.M.-A. have contributed in the same way to the writing of this manuscript, and both authors have read and approved the final manuscript.

Funding: This research received no external funding.

Conflicts of Interest: The authors declare no conflict of interest.

\section{References}

1. Au-Yong-Oliveira, M.; Gonçalves, R.; Martins, J.; Branco, F. The social impact of technology on millennials and consequences for higher education and leadership. Telemat. Inform. 2018, 35, 954-963. [CrossRef]

2. Alshuwaikhat, H.M.; Adenle, Y.A.; Saghir, B. Sustainability Assessment of Higher Education Institutions in Saudi Arabia. Sustainability 2016, 8, 750. [CrossRef]

3. García-Peñalvo, F.J.; Fidalgo-Blanco, Á.; Sein-Echaluce, M.L. An adaptive hybrid MOOC model: Disrupting the MOOC concept in higher education. Telemat. Inform. 2018, 35, 1018-1030. [CrossRef]

4. Moreira, F.; Ferreira, M.J.; Santos, C.P.; Durão, N. Evolution and use of mobile devices in higher education: A case study in Portuguese Higher Education Institutions between 2009/2010 and 2014/2015. Telemat. Inform. 2017, 34, 838-852. [CrossRef]

5. Kang, D.; Park, M.J. Competitive prospects of graduate program on the integration of ICT superiority, higher education, and international aid. Telemat. Inform. 2017, 34, 1625-1637. [CrossRef]

6. Aparicio-Martínez, P.; Perea-Moreno, A.J.; Martinez-Jimenez, M.P.; Varo, I.S.V.; Vaquero-Abellán, M. Social networks' unnoticed influence on body image in Spanish university students. Telemat. Inform. 2017, 34, 1685-1692. [CrossRef]

7. Ramirez, G.M.; Collazos, C.A.; Moreira, F. All-Learning: The state of the art of the models and the methodologies educational with ICT. Telemat. Inform. 2018, 35, 944-953. [CrossRef]

8. Bermejo, S. Cooperative electronic learning in virtual laboratories through forums. IEEE Trans. Educ. 2005, 48, 140-149. [CrossRef]

9. Cabedo, L.; Royo, M.; Moliner, L.; Guraya, T. University social responsibility towards engineering undergraduates: The effect of methodology on a service-learning experience. Sustainability 2018, 10, 1823. [CrossRef]

10. Heradio, R.; de la Torre, L.; Dormido, S. Virtual and remote labs in control education: A survey. Annu. Rev. Control. 2016, 42, 1-10. [CrossRef]

11. Jiménez-Torres, M.; Rus-Casas, C.; Lemus-Zúiga, L.G.; Hontoria, L. The Importance of Accurate Solar Data for Designing Solar Photovoltaic Systems-Case Studies in Spain. Sustainability 2017, 9, 247. [CrossRef]

12. Ko, C.C.; Chen, B.M.; Hu, S.; Ramakrishnan, V.; Cheng, C.D.; Zhuang, Y.; Chen, J. A web-based virtual laboratory on a frequency modulation experiment. IEEE Trans. Syst. Man Cybern. Part C (Appl. Rev.) 2001, 31, 295-303.

13. Paredes-Labra, J.; Siri, I.M.; Oliveira, A. Preparing Public Pedagogies with ICT: The Case of Pesticides and Popular Education in Brazil. Sustainability 2018, 10, 3377. [CrossRef]

14. Zajko, K.; Bradač Hojnik, B. Social Franchising Model as a Scaling Strategy for ICT Reuse: A Case Study of an International Franchise. Sustainability 2018, 10, 3144. [CrossRef]

15. Gravier, C.; Fayolle, J.; Bayard, B.; Ates, M.; Lardon, J. State of the art about remote laboratories paradigms-foundations of ongoing mutations. Int. J. Online Eng. 2008, 4, 19-25.

16. Potkonjak, V.; Gardner, M.; Callaghan, V.; Mattila, P.; Guetl, C.; Petrović, V.M.; Jovanović, K. Virtual laboratories for education in science, technology, and engineering: A review. Comput. Educ. 2016, 95, 309-327. [CrossRef] 
17. Merchant, Z.; Goetz, E.T.; Cifuentes, L.; Keeney-Kennicutt, W.; Davis, T.J. Effectiveness of virtual reality-based instruction on students' learning outcomes in K-12 and higher education: A meta-analysis. Comput. Educ. 2014, 70, 29-40. [CrossRef]

18. Salmerón-Manzano, E.; Manzano-Agugliaro, F. Worldwide scientific production indexed by Scopus on Labour Relations. Publications 2017, 5, 25. [CrossRef]

19. Bar-Ilan, J. Citations to the "Introduction to informetrics" indexed by WOS, Scopus and Google Scholar. Scientometrics 2010, 82, 495-506. [CrossRef]

20. Mongeon, P.; Paul-Hus, A. The journal coverage of Web of Science and Scopus: A comparative analysis. Scientometrics 2016, 106, 213-228. [CrossRef]

21. Archambault, É.; Campbell, D.; Gingras, Y.; Larivière, V. Comparing bibliometric statistics obtained from the Web of Science and Scopus. J. Am. Soc. Inf. Sci. Technol. 2009, 60, 1320-1326. [CrossRef]

22. Gimenez, E.; Salinas, M.; Manzano-Agugliaro, F. Worldwide research on plant defense against biotic stresses as improvement for sustainable agriculture. Sustainability 2018, 10, 391. [CrossRef]

23. De la Cruz-Lovera, C.; Perea-Moreno, A.J.; de la Cruz-Fernández, J.L.; Alvarez-Bermejo, J.A.; Manzano-Agugliaro, F. Worldwide research on energy efficiency and sustainability in public buildings. Sustainability 2017, 9, 1294. [CrossRef]

24. Gimenez, E.; Manzano-Agugliaro, F. DNA Damage Repair System in Plants: A Worldwide Research Update. Genes 2017, 8, 299. [CrossRef] [PubMed]

25. Hernández-Escobedo, Q.; Perea-Moreno, A.J.; Manzano-Agugliaro, F. Wind energy research in Mexico. Renew. Energy 2018, 123, 719-729. [CrossRef]

26. Van Eck, N.; Waltman, L. Software survey: VOSviewer, a computer program for bibliometric mapping. Scientometrics 2009, 84, 523-538. [CrossRef] [PubMed]

27. Paskin, N. Digital object identifier $\left(\mathrm{DOI}^{\circledR}\right)$ system. Encycl. Libr. Inf. Sci. 2010, 3, 1586-1592.

28. Verborgh, R.; De Wilde, M. Using OpenRefine; Packt Publishing Ltd.: Birmingham, UK, 2013.

29. El Khaled, D.; Novas, N.; Gazquez, J.A.; Manzano-Agugliaro, F. Dielectric and bioimpedance research studies: A Scientometric approach using the scopus database. Publications 2018, 6, 6. [CrossRef]

30. Montoya, F.; Baños, R.; Alcayde, A.; Montoya, M.; Manzano-Agugliaro, F. Power Quality: Scientific Collaboration Networks and Research Trends. Energies 2018, 11, 2067. [CrossRef]

31. Garrido-Cardenas, J.A.; Mesa-Valle, C.; Manzano-Agugliaro, F. Trends in plant research using molecular markers. Planta 2017, 247, 543-557. [CrossRef] [PubMed]

32. Garrido-Cardenas, J.A.; Mesa-Valle, C.; Manzano-Agugliaro, F. Genetic approach towards a vaccine against malaria. Eur. J. Clin. Microbiol. Infect. 2018, 37, 1829-1839. [CrossRef] [PubMed]

33. Garrido-Cardenas, J.A.; Mesa-Valle, C.; Manzano-Agugliaro, F. Human parasitology worldwide research. Parasitology 2018, 145, 699-712. [CrossRef] [PubMed]

34. Salmerón-Manzano, E.M. Análisis de las competencias genéricas de la Universidad de Almería en el Grado en Derecho en relación al mercado laboral. Espiral Cuadernos Profesorado 2017, 10, 58-72. [CrossRef]

35. MECD. 2016. Available online: https://www.mecd.gob.es/dms/mecd/servicios-al-ciudadano-mecd/ estadisticas/educacion/universitaria/datos-cifras/datos-y-cifras-SUE-2015-16-web-.pdf (accessed on 10 August 2018).

36. Allen, I.E.; Seaman, J. Changing Course: Ten Years of Tracking Online Education in the United States. 2013; p. 47. Available online: https:/ / files.eric.ed.gov/fulltext/ED541571.pdf (accessed on 10 August 2018).

37. Aznar-Sánchez, J.A.; Belmonte-Ureña, L.J.; Velasco-Muñoz, J.F.; Manzano-Agugliaro, F. Economic analysis of sustainable water use: A review of worldwide research. J. Clean. Prod. 2018, 198, 1120-1132. [CrossRef]

38. Salmeron-Manzano, E.; Manzano-Agugliaro, F. The Electric Bicycle: Worldwide Research Trends. Energies 2018, 11, 1894. [CrossRef]

39. Redel-Macías, M.D.; Pinzi, S.; Martínez-Jiménez, M.P.; Dorado, G.; Dorado, M.P. Virtual laboratory on biomass for energy generation. J. Clean. Prod. 2016, 112, 3842-3851. [CrossRef]

40. Pérez-Romero, A.M.; Castro-Garcia, M.; León-Bonillo, M.J.; Manzano-Agugliaro, F. Learning effectiveness of virtual environments for 3D terrain interpretation and data acquisition. Surv. Rev. 2017, 49, 302-311. [CrossRef]

41. Manzano-Agugliaro, F.; Salmerón-Manzano, E.; Perea-Moreno, A.J. Las competencias transversales de las universidades del campus de excelencia agroalimentario (CEI-A3). Espiral Cuadernos Profesorado 2016, 4, 3-12. [CrossRef] 
42. Padilla, F.M.; Gallardo, M.; Manzano-Agugliaro, F. Global trends in nitrate leaching research in the 1960-2017 period. Sci. Total. Environ. 2018, 643, 400-413. [CrossRef] [PubMed]

43. Garrido-Cardenas, J.A.; Manzano-Agugliaro, F.; Acien-Fernandez, F.G.; Molina-Grima, E. Microalgae research worldwide. Algal Res. 2018, 35, 50-60. [CrossRef]

44. Montoya, F.G.; Alcayde, A.; Baños, R.; Manzano-Agugliaro, F. A fast method for identifying worldwide scientific collaborations using the Scopus database. Telemat. Inform. 2018, 35, 168-185. [CrossRef]

45. Garcia-Zubia, J.; Cuadros, J.; Romero, S.; Hernandez-Jayo, U.; Orduña, P.; Guenaga, M.; Gustavsson, I. Empirical analysis of the use of the VISIR remote lab in teaching analog electronics. IEEE Trans. Educ. 2017, 60, 149-156. [CrossRef]

46. Dormido, S. Control learning: Present and future. Annu. Rev. Control. 2004, 28, 115-136.

47. Shin, D.H. The role of affordance in the experience of virtual reality learning: Technological and affective affordances in virtual reality. Telemat. Inform. 2017, 34, 1826-1836. [CrossRef]

48. Manzano-Agugliaro, F.; Castro-García, M.; Pérez-Romero, A.M.; García-Cruz, A.; Novas, N.; Salmerón-Manzano, E. Alternative methods for teaching cadastre and remote sensing. Surv. Rev. 2016, 48, 450-459. [CrossRef]

49. Salmerón-Manzano, E.; Alcayde, A.; Montoya, F.G.; Novas Castellano, N.; García-Salvador, R.; Garrido-Cárdenas, J.A.; Martínez-Lao, J.A.; Zapata-Sierra, A.J.; Fernández-Ros, M.; Soler-Ortiz, M.; et al. Smartphone as an interactive learning tool: Assessment of the use in university teaching. In Proceedings of the 10th International Conference on Education and New Learning Technologies, Palma, Spain, 2-4 July 2018; pp. 3607-3614.

50. Virtanen, M.A.; Kääriäinen, M.; Liikanen, E.; Haavisto, E. The comparison of students' satisfaction between ubiquitous and web-basedlearning environments. Educ. Inf. Technol. 2017, 22, 2565-2581. [CrossRef]

51. Huang, Y.C.; Backman, S.J.; Backman, K.F.; McGuire, F.A.; Moore, D. An investigation of motivation and experience in virtual learning environments: A self-determination theory. Educ. Inf. Technol. 2018, in press. [CrossRef]

52. Case, J.M.; Light, G. Emerging research methodologies in engineering education research. J. Eng. Educ. 2011, 100, 186-210. [CrossRef]

53. Singer, S.; Smith, K.A. Discipline-based education research: Understanding and improving learning in undergraduate science and engineering. J. Eng. Educ. 2013, 102, 468-471. [CrossRef]

54. Hayward, P.A. A comparison of face-to-face and virtual software development teams. Team Perform. Manag. Int. J. 2002, 8, 39-48.

55. Hoegl, M.; Proserpio, L. Team member proximity and teamwork in innovative projects. Res. Policy 2004, 33, 1153-1165. [CrossRef]

56. Koretsky, M.D.; Amatore, D.; Barnes, C.; Kimura, S. Enhancement of student learning in experimental design using a virtual laboratory. IEEE Trans. Educ. 2008, 51, 76-85. [CrossRef]

57. Purvanova, R.K.; Bono, J.E. Transformational leadership in context: Face-to-face and virtual teams. Leadersh. Q. 2009, 20, 343-357. [CrossRef]

58. Velosa-García, J.D.; Castillo-García, F.J.; Espíldora, E.; Cobo, L. Requirements for hybrid laboratories in Manufacturing Engineering. Dyna 2017, 84, 65-74. [CrossRef]

59. Perea-Moreno, A.J.; Salmerón-Manzano, E.M.; Laguna-Luna, A.M.; Aguilera-Ureña, M.J.; Manzano-Agugliaro, F. Experiencias de aprendizaje activo mediante Clickers en prácticas universitarias. Espiral Cuadernos Profesorado 2017, 10, 16-27. [CrossRef]

60. Lang, D.; Mengelkamp, C.; Jaeger, R.S.; Geoffroy, D.; Billaud, M.; Zimmer, T. Pedagogical evaluation of remote laboratories in eMerge project. Eur. J. Eng. Educ. 2007, 32, 57-72. [CrossRef]

61. Kara, A.; Ozbek, M.E.; Cagiltay, N.E.; Aydin, E. Maintenance, sustainability and extendibility in virtual and remote laboratories. Procedia Soc. Behav. Sci. 2011, 28, 722-728. [CrossRef]

62. Wiedmann, T. An input-output virtual laboratory in practice-survey of uptake, usage and applications of the first operational IELab. Econ. Syst. Res. 2017, 29, 296-312. [CrossRef]

(C) 2018 by the authors. Licensee MDPI, Basel, Switzerland. This article is an open access article distributed under the terms and conditions of the Creative Commons Attribution (CC BY) license (http://creativecommons.org/licenses/by/4.0/). 